Illinois State University

ISU ReD: Research and eData

Theses and Dissertations

$12-10-2013$

\title{
Exploring Factors that Influence the Choice to Retire from Driving in Older Adults
}

Debra J. Jenkins

Illinois State University, djenki2014@gmail.com

Follow this and additional works at: https://ir.library.illinoisstate.edu/etd

Part of the Nursing Commons

\section{Recommended Citation}

Jenkins, Debra J., "Exploring Factors that Influence the Choice to Retire from Driving in Older Adults" (2013). Theses and Dissertations. 82.

https://ir.library.illinoisstate.edu/etd/82

This Dissertation is brought to you for free and open access by ISU ReD: Research and eData. It has been accepted for inclusion in Theses and Dissertations by an authorized administrator of ISU ReD: Research and eData. For more information, please contact ISUReD@ilstu.edu. 


\title{
EXPLORING FACTORS THAT INFLUENCE THE CHOICE \\ TO RETIRE FROM DRIVING \\ IN OLDER ADULTS
}

\author{
Debra J. Jenkins
}

82 Pages

May 2014

Purpose: Automobile accidents are the second leading cause of injury in older adults, escalating with age. These accidents can be related to diminish cognitive skills, presence of depressive symptoms, limited or lack of social support, and declining functional abilities. However, few studies have examined the relationship and inter-relationship between these factors and their impact on the choice to retire from driving. Therefore, the purpose of this retrospective, descriptive study is to (1) describe the characteristics of older adult drivers, residing in the community, who choose to retire from driving or continue to drive; (2) determine if a relationship or inter-relationship between the variables of cognitive skills, depressive symptom, social support and functional abilities are influential in the choice to retire or continue to drive, and (3) identify what variables predict the choice to retire from driving or continue to drive.

Theoretical Framework: The CHOICE model was developed to conceptualize the choice to either retire or continue to drive using the four identified major factors. 
Design, sample, and setting: The study used a convenience sample consisting of 151 community-dwelling adults age 60 and older.

Methods: Participants were measured with the Repeatable Battery and Neuropsychological Status exam, Trails Making Test Part B, Geriatric Depression Scale, gait, and handgrip strength. Data were analyzed using descriptive statistics, point biserial correlations, $X^{2}$, and logistic regression.

Major findings: Gender was not statistically significant in driving retirement; the relationships between variables directly related to driving status were weak or nonsignificant but interrelationships between variables were significant, and two logistic regression models were predictive of driving retirement.

Conclusion: This study is foundational in understanding the CHOICE to retire from driving. Future studies should include additional variables of social support and functional abilities to enhance the understanding of driving retirement in older adults. 
EXPLORING FACTORS THAT INFLUENCE THE CHOICE

TO RETIRE FROM DRIVING

IN OLDER ADULTS

DEBRA J. JENKINS

A Dissertation Submitted in Partial

Fulfillment of the Requirements

for the Degree of

DOCTOR OF PHILOSOPHY

Mennonite College of Nursing

ILLINOIS STATE UNIVERSITY

2014 
All rights reserved

INFORMATION TO ALL USERS

The quality of this reproduction is dependent upon the quality of the copy submitted.

In the unlikely event that the author did not send a complete manuscript and there are missing pages, these will be noted. Also, if material had to be removed, a note will indicate the deletion.

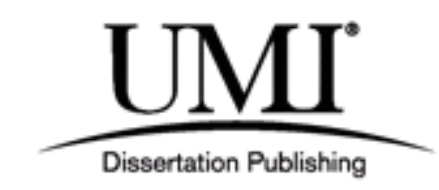

UMI 3623419

Published by ProQuest LLC (2014). Copyright in the Dissertation held by the Author.

Microform Edition (C) ProQuest LLC.

All rights reserved. This work is protected against unauthorized copying under Title 17, United States Code

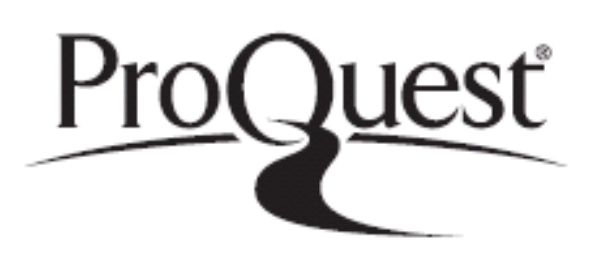

ProQuest LLC.

789 East Eisenhower Parkway

P.O. Box 1346

Ann Arbor, MI 48106 - 1346 
(C) 2014 Debra J. Jenkins 
EXPLORING FACTORS THAT INFLUENCE THE CHOICE

TO RETIRE FROM DRIVING

IN OLDER ADULTS

DEBRA J. JENKINS

COMMITTEE MEMBERS:

Wendy Woith, Chair

Caroline Mallory

Sheryl Jenkins

Leroy Hall 


\section{ACKNOWLEDGEMENTS}

I would like to thank my committee members Drs. Caroline Mallory, Sheryl Jenkins, and Lee Hall. Your support and feedback enabled me to have a successful dissertation. I, especially, want to thank Dr. Wendy Woith for her patience and guidance during this last "dash to the finish line." I never thought I would actually finish this process. Next, I would be remiss to not give a great big gratitude to, my husband, Leonard, for his unwavering love, support, patience and ability to make dinner arrangements. Starving during this process may have deterred the outcome. I would like to thank my parents, Brice and Lorraine, for their love and support throughout this process. When I wanted to "throw in the towel," they were always there to tell me "keep going and everything will work out." My sister, Cheryl, and her infinite computer wisdom enabled me to have a correctly formatted document. Finally, my daughter and son-in-law deserve my gratitude. They always understood if I could not attend a family event or needed to bring my computer.

Finally, I would like to dedicate this dissertation to my two former advisors, Drs.

Ezra C. Holston and Elizabeth D. Carlson. They set me on this path exploring driving in older adults. I will say I was skeptical at first but they had the foresight to see that this topic was deserving of nursing research. I will always be indebted to them.

D. J. J. 


\section{CONTENTS}

Page

ACKNOWLEDGMENTS $\quad$ i

$\begin{array}{ll}\text { CONTENTS } & \text { ii }\end{array}$

TABLES $\quad$ V

FIGURES vi vi

\section{CHAPTER}

I. INTRODUCTION 1

Research Questions/Hypotheses 4

Conceptual Definitions 4

Choice 4

Cognitive Skills $\quad 5$

Social Support $\quad 5$

Depressive Symptoms

Functional Abilities $\quad 5$

Older Adults $\quad 6$

Drivers $\quad 6$

Non-drivers $\quad 6$

$\begin{array}{ll}\text { Summary } & 7\end{array}$

II. $\quad$ REVIEW OF LITERATURE 8

$\begin{array}{ll}\text { Integrative Review of the Literature } & 8\end{array}$

Choice $\quad 8$

The Relationship Between Choice and Cognitive Skills 9

$\begin{array}{ll}\text { Structural components and neural pathways. } & 10\end{array}$ 
Executive cognitive functions.

Cognitive processes of accommodation, assimilation, and fluency.

The Relationship Between Choice and Depressive Symptoms

The Relationship Between Choice, Social Support, and

Cognitive Skills

The Relationship Between Choice and Functional Abilities

The CHOICE Framework

Analytical Review of the Literature

Choice

Choice and Driving Retirement

Significance to Gerontological Research

III. METHODS 36

Elements of Research Study $\quad 36$

Design $\quad 36$

Sample $\quad 36$

Setting $\quad 37$

Procedure $\quad 37$

Protection of Human Subjects $\quad 39$

Instruments/Measurements 41

Explanation of Instruments/Measurements $\quad 42$

Choice. $\quad 42$

Sample characteristics. $\quad 42$

Cognitive skills. $\quad 42$

Depressive symptoms. $\quad 45$

Functional abilities. $\quad 46$

$\begin{array}{ll}\text { Analysis of the Data } & 47\end{array}$

IV. RESULTS 49

$\begin{array}{ll}\text { Descriptive Analyses } & 49\end{array}$

Description of the Sample $\quad 49$ 
Description of Cognitive Status $\quad 50$

Description of Depressive Symptoms $\quad 54$

Description of Functional Abilities $\quad 54$

Relationships Among Variables 55

Predicting Driving Retirement 57

$\begin{array}{lll}\text { V. DISCUSSION } & 62\end{array}$

Research Question One $\quad 62$

Research Question Two 66

Research Question Three $\quad 68$

Limitations of Study $\quad 68$

$\begin{array}{ll}\text { Conclusions } & 70\end{array}$

Implications and Recommendations for Future Research $\quad 70$

$\begin{array}{ll}\text { REFERENCES } & 71\end{array}$

APPENDIX: CONFIDENTIALITY AGREEMENT WITH PSYCHOLOGY

SPECIALISTS, LTD 81 


\section{TABLES}

Table

Page

1. Study Variables and Instruments/Measurements 41

2. RBANS Indexes with Associated Subtests 44

3. Demographic Characteristics of the Sample 50

4. Means, Standard Deviations, and Ranges for each RBANS Index 51

5. Frequencies and Percentages by RBANS Indexes for Non-Drivers
$(\mathrm{n}=55)$

6. Frequencies and Percentages by RBANS Indexes for Drivers $(\mathrm{n}=96)$

7. Frequencies and Percentages per Classification of Impairment for Trails B

8. Frequencies and Percentages of Handgrip Strength in Dominant and Non-Dominate Hand

9. Correlations Among Driving Status, RBANS Indexes, GDS, and Trails B

10. Chi-square Analysis of Age, Gender, Marital Status, Handgrip, and Gait

11. Univariate Statistics for Logistic Regression 60

12. Multivariate Statistics for Logistic Regression 61 


\section{FIGURES}

Figure $\quad$ Page

1. Building the CHOICE Framework 16

2. Building the CHOICE Framework 19

3. The CHOICE Framework 22

4. Regression Analysis Using the Independent Variables of the CHOICE Framework 


\section{CHAPTER I \\ INTRODUCTION}

Driving in older adults is a challenging public health concern. Automobile accidents are the second leading cause of injury in older adults and the risk for injury escalates with age (Lantz, 2007; National Highway Traffic Safety Association [NHTSA], 2010); only teen drivers have a greater risk for injury (NHTSA, 2013). According to the Centers for Disease Control and Prevention (CDC), in 2008 over 5,500 older adults died as a result of automobile crashes and another 185,000 were injured. This equates to 15 older adults killed and 500 injured in crashes daily. Medical costs of older driver related injuries are nearly $\$ 9$ million annually (Older adult drivers, n.d.). The identified costs are limited to older drivers and do not include medical costs of passengers or members in other motor vehicles. The inclusion of passenger and drivers or passengers in other motor vehicles further increases the costs. Conversely, the Insurance Institute for Highway Safety (2014), older driver crash rate per licensed driver is trending downward, the fatal crash rate for older driver per mile driven remains high but the most recent evidence indicates middle-age adults' fatal crash rate may be trending upward. In older adults the fatalities may be due to frailty issues resulting from the aging process. 
According to the NHTSA (2013) report, mental and functional changes associated with the aging process contribute to older adults' driving behaviors. Older adults change their driving behaviors by reducing their speed irrespective of traffic flow, driving in familiar areas which may be more congested, during good weather, and daytime hours. Additionally, older drivers have difficulties with left turns and merging with traffic contributing to their risk for serious or fatal injury, especially in the head and thorax area. These behaviors increase their risk for injury rather than reduce it (Baldock, Mathias, McLean, \& Berndt, 2006; Croston, Meuser, Berg-Weger, Grant, \& Carr, 2009; Donorfio, D'Ambrosio, Coughlin, \& Mobyde, 2008; Donorfio, Mobyde, Coughlin, \& D'Ambrosio, 2008; Molnar \& Elry, 2009; Ragland, Satariano, \& MacLeod, 2004). With an aging population, the incidence of driving related injury and/or death are likely to increase.

Individuals, irrespective of age, make multiple choices daily ranging from the routine, "What should I eat for supper tonight?" to risky choices, "I am late for work so I better drive faster," to complex choices, such as "Is it time to retire from driving?" (Botti, Orfali, \& Iyengar, 2009; Bush, Morris, Millham, \& Issacson, 2011). In our daily conversations, the word choice is used indiscriminately with little awareness of the complexity involved (Baker, 2006; Ha, Park, \& Ahn, 2009; Milder, Lipworth, Williams, Ritchie, \& Day, 2011; Schrift, Netzer, Kivetz, 2011). Researchers have found that the choice to retire from driving is a complex phenomenon; however, there is little research to clarify how to address this issue. Therefore the problem persists, leaving older adults at risk for injury or death. 
Driving has a close association with independence, making retirement from driving difficult for many older adults (Adler \& Rottunda, 2006). Central to this issue is "choice." For many adults, making the choice to retire from driving has an emotional impact similar to choices associated with end-of-life (Carr \& Moorman, 2009) and changes in living arrangements (Bekhet, Zauszniewski, \& Nakhla, 2009; Rossen, 2007). Socially, older adults are expected to accept driving retirement without consideration of the emotional loss of independence driving fulfills; emotional maturity, mobility, and self-reliance (Eby \& Molnar, 2008).

Many older adults choose to continue to drive irrespective of skills. The literature suggests four factors affect the concept of choice: cognitive skills, depressive symptoms, social support, and functional abilities. When an older adult becomes aware their driving skills are diminishing, some retire from driving easily, others reduce their driving to limit times and/or places, and still others continue to drive. These three scenarios appear to relate to the outcome of choice, but understanding the differences between the scenarios remains unclear. Although the literature reports multiple studies related to older adult drivers, this study is unique because it places driving retirement in the context of choice. Therefore, the purpose of this descriptive, retrospective, crosssectional study is to explore the relationship between these factors (cognitive skills, depressive symptoms, social support, and functional abilities) and their impact on the choice to retire from driving for older adults residing in the community. 


\section{Research Questions/Hypotheses}

1. What are the characteristics of older adult drivers, residing in the community, who choose to retire from driving or continue to drive?

2. a. What is the relationship between the four independent variables (cognitive skills, depressive symptoms, social support, and functional abilities) and the choice to retire from driving or continue to drive?

b. Is there an inter-relationship between the four independent variables (cognitive skills, depressive symptoms, social support, and functional abilities) that is more influential in the choice to retire from driving or continue to drive?

3. What variables (cognitive skills, depressive symptoms, social support, and functional abilities) predict the choice to retire from driving or continue to drive?

\section{Conceptual Definitions}

The conceptual definitions of terms ensure consistency throughout the document and data collection.

\section{Choice}

Choice is "the act of choosing or selection; the power of choosing or option" (Merriam-Webster, 2012). Choice results from the options presented in the decision process; however, an individual's gravitation to one option over the others derives from the emotions and/or values ascribed to that option (Ha et al., 2009; Han, 2007). Operationally, choice will be measured as the individual's declared driving status, either driver or non-driver. 


\section{Cognitive Skills}

Conceptually, cognitive skills can be defined as structures and chemical processes within the brain that enables the individual to problem solve, function within, and adapt to their environment (Lezak, Howieson, \& Loring, 2004). Cognitive skills appear to slow with aging, but changes attributed to visuospatial (reaction time), attention, and/or mental flexibility may be indicative of disease.

\section{Social Support}

Relationships with other individuals develop throughout one's lifetime. Support derived from these relationships assists the individual to cope with stress and adapt to change (Jones \& Nystrom, 2012; Lindsey \& Yates, 2004; Masini \& Barrett, 2012). In the driving literature, family and close friends are often used as primary examples of social support.

\section{Depressive Symptoms}

For the purpose of this study, depressive symptoms are conceptually defined as a cluster of physical and emotional symptoms, which includes feelings of sadness, loss, fatigue (both mental and physical), changes in sleep and eating patterns, frequent headaches, and chronic pain (National Institute of Mental Health, 2010).

\section{Functional Abilities}

Functional abilities are a "broad range of abilities that refer to the actual or potential capacity to perform the activities and tasks normally expected of an adult" (Richmond, Tang, Tulman, Fawcett, \& McCorkle, 2004, p. 84). The literature reports functional abilities associated with driving are vision, head and neck rotation for visual 
scanning, and muscle strength of both upper and lower limbs (Bladock et al., 2006; Carr, Flood, Steger-May, Schechtman, \& Binder, 2006(a); Tuokko, Rhodes, \& Dean, 2007).

\section{Older Adults}

According to Erikson (1982), older adults mature into a stage of ego-integrity versus despair usually around the age of 60 . In this developmental phase, an older adult

strives to adapt to changes in the cognitive, functional, social, and emotional aspects of their life by using successful strategies acquired throughout their life (Lange, 2012; Marcia \& Josselson, 2013). Intuitively, the successful adaptation strategies enable the older adult to maintain a sense of independence or ego-integrity. Erikson (1982) explained once an individual encounters limitations or strategies for that adaptation fail, in any or all of these areas, independence is lost and despair follows.

\section{Drivers}

Building on the conceptual definition of older adult, driving is an example of an older adult's independence, and therefore an expression of ego-integrity. For the purposes of this study, a driver is an older adult who continues to maintain ego-integrity, ergo independence, through their continuation of driving.

\section{Non-drivers}

Building on the conceptual definition of older adults and drivers, one might assume that an older adult who no longer drives may have issues of despair. Although inclusive in the literature, older adults may or may not retain their ego-integrity or feelings of independence once they no longer drive. For the purpose of this study, the conceptual definition of a non-driver is an older adult who no longer drives a motor vehicle. 


\section{Summary}

This chapter highlights the scope of the problem of older drivers in the United States. Through this discussion, research questions were identified to examine the problem. Conceptual definitions were provided to guide the consistency of the study. 


\section{CHAPTER II}

\section{REVIEW OF LITERATURE}

This chapter consists of a review of the literature and discussion of the conceptual framework that will provide the conceptualization of the problem in greater detail. The review of literature, both integrative and analytical, will offer more in-depth explanation of the problem, identify factors that impact the problem, and provide a framework to illustrate potential relationships among the factors and on the choice to retire from driving.

\section{Integrative Review of the Literature}

\section{Choice}

Choice is "the act of choosing or selection; the power of choosing or option" (Merriam-Webster, 2012). A choice results from the options presented in the decision process. The decision process involves two phases: pre- and post-decision (Tversky \& Kahneman, 1981). Tversky and Kahneman (1981) described the pre-decision phase as the time an individual recognizes options or choices and weighs each choice based on several factors. The pre-decision phase infers an individual possesses cognitive skills of comprehension, language, and memory to perform this phase. Comprehension allows the individual to understand the options and the differences between or among options. Language skills aid comprehension through meaning associated with the options 
Memory, either immediate or delayed, enables the individual to apply previous experience and place the option or choice within the context of the current situation. An individual obtains comprehension and language skills through education, which should parallel one's cognitive aptitude. However, years of education are not conclusively indicative of the cognitive aptitude due to issues like social progression within the education system, the quality of the education, or individual effort or skills (Moore et al., 2011). An educational experience can limit cognitive resources and impair the ability to make rational decisions. Furthermore, emotions ascribed to a choice may influence an individual's gravitation to one choice over the others (Ha et al., 2009; Han, 2007). Life experiences, previous and/or current, may intensify or diminish the ability to objectively weigh options, resulting in either an optimal or sub-optimal choice (Morrell, 2004). Additionally, when several options or choices are present, individual values, goals, and prior strategies enable the individual to select the "optimal" choice in the presenting situation (Henwood, Harris, \& Spoel, 2011). Therefore, making a choice, the post decision phase, entails more than cognitive skills. Emotions and cognitive skills appear to have a relationship influencing the outcome of choosing.

\section{The Relationship Between Choice and Cognitive Skills}

Cognitive skills are defined as structures and chemical processes within the brain that enable the individual to problem solve, function within, and adapt to their environment (Lezak et al., 2004). Philosophically, the mind operates logically, reasonably, and objectively (Rogers, 2005), thereby implying that an individual weighs options objectively and makes appropriate decisions. Often, individuals place options 
within a framework of risk versus benefit (Midler et al., 2011). This framework allows the individual to use previous experience and knowledge to choose, irrespective of outcome. To explain this relationship between choice and cognitive skills in greater detail necessitates a discussion of the structural components and executive functions of the brain and the process of assimilation, accommodation, and fluency.

Structural components and neural pathways. During the evolutionary process of the human brain, the growth of the forebrain, or cerebrum, allowed humans to develop certain capabilities such as reasoning and problem solving. Embedded in the lower part of the cerebrum is the limbic system. This area of the brain has an important role in emotion, motivation, and memory (Lezak et al., 2004). Baillene (2007) reported that choice is a process consisting of cognitive activity and behavioral activation as demonstrated by the stimulation of the limbic system and other cortical structures related to reward or simply emotions. Therefore, choice, cognitive functioning, and emotion are related.

Executive cognitive functions. The executive brain functions are receptive, input, memory or storage and retrieval, the thinking function or processing, and expression or output (Lezak et al., 2004). The receptive function involves abilities to select, acquire, classify, and integrate information. Memory and learning functions refer to information storage and retrieval. The thinking function involves organizing information. Finally, expression allows for communication of or action on the information (Lezak et al., 2004). While each executive brain function has a distinct role, it is the collective combination of these functions that result in an individual's ability to 
objectively weigh options or choices (Milder et al., 2011), allowing the individual to frame choices within the context of their understanding. The combination of these functions are also linked to driving ability (Alexandersen, Dalen, \& Bronnick, 2009; Ball et al., 2006; Edwards, Perkins, Ross, \& Reynolds, 2009). The identified structures and neural components of the brain alone do not entirely explain an individual's ability to make choices. When choices are presented, the individual may rely on previously learned information for framing the context of the situation and enabling the individual to make an appropriate choice. Consequently, choices appear to have a linkage with learning in the process of assimilation, accommodation, and fluency.

Cognitive processes of accommodation, assimilation, and fluency. Morrell (2004) posited that cognitive skills alone cannot explain the process of choosing. Cognitive skills provide individuals with the ability to weigh the options presented and then objectively choose. Options or choices are often self-limiting due to the number presented causing an individual to categorize their options according to risk versus benefit (Ha et al., 2009). This allows individuals to use previous experiences and knowledge (assimilation) to weigh options and ultimately make a choice (accommodation).

According to Olson and Hergenhahn (2009) and Herzog (2009), an individual's ability to acquire knowledge changes over time through physical, psychological, social, and spiritual maturation. Both, Olson and Hergenhahn (2009) and Herzog (2009) described cognitive maturation as a dynamic process between biological maturation and interaction with the environment. This dynamic process enables the individual to 
associate previous knowledge (assimilation) with a new experience and formulate a connection (accommodation).

Many choices are encountered over a lifetime, from the mundane choice of what to eat for dinner to the more complex such as choosing a type of surgery (Bush et al., 2011), to emotion-laden choices or tragic choices, such as withdrawing life support (Botti et al., 2009). Thus, accommodation occurs because the individual assimilated the option or choice based on previous experience or knowledge and changed their cognitive processes resulting in fluency.

Fluency or automaticity describes the cognitive process that results from assimilation and accommodation (Johnson \& Layng, 1992). When a task becomes automatic, it becomes useful, remembered, and applied. Johnson and Layng (1992) explained that until a task becomes automatic, the task requires greater cognitive demands. For most individuals, the choice about what to eat is an automatic experience and not a life-altering one. The onset of hunger pains automatically leads to eating. Other fluent activities are tying shoelaces, reading a novel, learning basic math skills, and driving. Fluency appears to require minimal intentional cognitive processing and continues until one's cognitive processes begin to diminish. Thus, cognitive decline results in less fluidity and greater cognitive demands with tasks.

Within the context of driving, cognitive skills and the ability to drive safely have a close association. The subset of cognitive skills such as visuospatial, attention, and mental flexibility, are associated with driving ability (Alexandersen et al., 2009; Ball et al., 2006; Edwards et al., 2009; Hirth, Davis, Fridriksson, \& Rorden, 2007; 
Ingley, Chinnaswamy, \& Devakumar, 2009). When these cognitive skills decline, cognitive workload increases and impacts this once fluent skill to become more tasking. With diminishing cognitive skills, the process of choosing may become challenging and choices, particularly multiple ones, become overwhelming (Gurland, Gurland, Mitty, \& Toner, 2009; Han, 2007). Often older adults report this increased cognitive workload as exhausting (Adams \& Beehr, 2003; Johnson, 1998; Ragland et al., 2004). Intuitively, when an option such as driving is linked cognitively to one's independence, emotion rather than logic may determine the choice. Ha et al. (2009) explained that individuals intuitively categorize options when multiple options are presented. Often, emotions have a greater influence on the categorization of the choices or options than cognitive processes. Han (2007) further explained emotions tend to "blur" cognitive skills in time of cognitive overload such as multiple options. In other words, emotions such as anger, labeled as a high-certainty emotion, are thought to impede cognitive skills whereas anxiety, a low-certainty emotion, had little to no effect. Therein lays the potential for variation of choice when cognitive skills cannot be separated from emotions, thus potentially impacting the choice to retire from driving.

\section{The Relationship Between Choice and Depressive Symptoms}

Globally, emotions affect choice either positively or negatively (Baker, 2006;

Burge \& Street, 2010; Federman, Wisinversky, Wolf, Leventhal, \& Halm, 2010;

Goodwin, Zhang, \& Ostir, 2004; Gumus et al., 2010; Gurland, \& Gurland(a), 2009;

Joon, Kim, Shanker, \& Han, 2004; Matsuoka et al., 2011; Visser et al., 2009; Wang, Novemsky, Dhar, \& Baumeister, 2010). Yet, the underpinnings of the relationship 
between choice and depressive symptoms arise from the interrelationship between choice, independence, and retirement, and therefore, these interrelationships require closer examination.

The emotions and ultimately the presence of depressive symptoms appear to arise from the association of independence and retirement and their potential link to selfconcept and quality of life (Gurland \& Gurland, 2009a; Gurland \& Gurland, 2009b). The emotional impact of confronting the issue of retiring from driving appears similar to retirement in general (Adams \& Beehr, 2003). An individual experiences three phases of retirement--pre-retirement, retirement, and post-retirement. During each phase of retirement, individuals report emotions ranging from grief to relief. According to Adams and Beehr (2003), the emotions often reported during the pre-retirement phase are dependent upon whether retirement is planned. When individuals are confronted with unplanned retirement, emotional responses are often reported as anger that may arise from loss-of-control and stress arising from their lack of involvement in the choice. The lack of involvement may manifest in the presence of depressive symptoms (Adler \& Rottunda, 2006). During the retirement and post-retirement phases, individuals report the need to grieve, even when retirement is planned (Adler \& Rottunda, 2006). The phases of retirement in general are similar to driving retirement. When retirement from driving is unplanned or "forced" choice, emotional responses of anger, sadness, diminished selfworth, and loss-of-control are reported leaving a person to grieve (Antsey, Windsor, Luszcz, \& Andrews, 2006; Johnson, 1998). Grieving is associated with the loss of independence driving provides (Johnson, 1998). Depending upon the duration, severity, 
and cumulative effect of unresolved grief, depressive symptoms may emerge (Delling, Sehgal, Sleet, \& Barrett-Connor, 2001; Johnson, 2008). When depressive symptoms emerge, cognitive skills may be affected (Castel, McCabe, \& Roediger, 2007) and successful measurement impacted (Barker, Horner, \& Bachman, 2010).

Depressive symptoms influence cognitive function in two significant ways. Depressive symptoms appear to be a mediating factor for over-estimating one's abilities. Individuals tend to be unrealistic and overconfident in their abilities to perform everyday activities (Castel et al., 2007). Research measuring overconfidence requires individuals to predict their ability to perform and rate their ability to perform the skill. The discrepancy between perceived and actual ability equates to overconfidence. In a study involving self-reported memory, functional abilities, and vision on self-regulation of driving abilities, Braitman and Williams (2011) found inconsistencies in self-reported abilities over a four-year period. Although not reported by the authors, their inconsistent findings may be a result of this phenomenon of overconfidence, which is regulated by depressive symptoms.

Secondly, the presence of depressive symptoms potentially influences measurements of cognitive skills since the individual may exert minimal effort during testing (Barker et al., 2010). As the number of depressive symptoms increases, neuropsychological testing measurement becomes less reliable due to the potential minimal effort of the individual. This lack of effort in combination with potential emotional problems resulting from the depressive symptoms potentially contributes to choice, yet the relationship remains unclear. The inter-relationship between depressive 
symptoms and cognitive skills appear to have a strong relationship but the relationship, individually and collectedly, on the choice to retire from driving is less clear (see Figure $1)$.

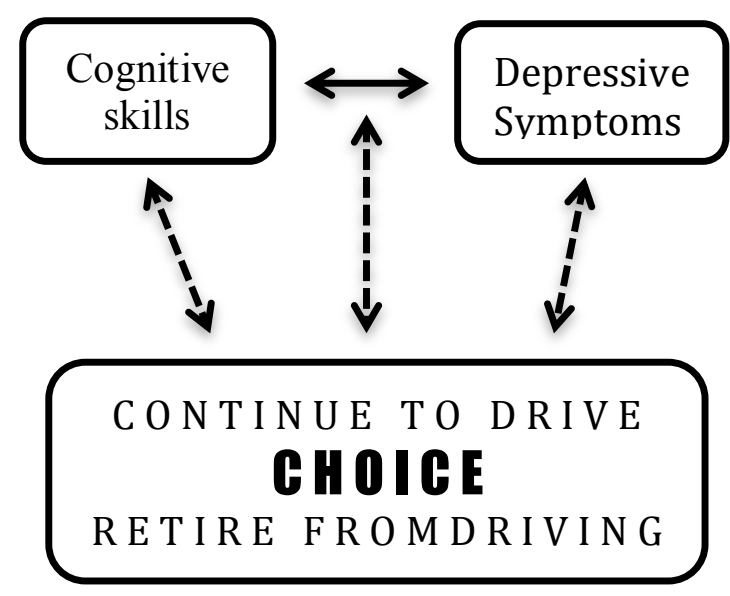

Figure 1. Building the CHOICE Framework

Cognitive skills and depressive symptoms appear to have a strong relationship depicted with a solid bi-directional arrow. The individual relationship with cognitive skills and depressive symptoms on the choice to retire from driving is less clear and depicted by a dotted bi-directional arrow between each concept and choice. The collective relationship between the two variables on the choice to retire from driving is less clear and is depicted by a bi-directional dotted arrow between the solid bidirectional arrow between the two concepts of cognitive skills and depressive symptoms.

The complexity of potentially unresolved depressive symptoms associated with retirement in general and driving retirement specifically has the potential to complicate one's cognitive capacity to make optimal choices and may compel the individual to seek out external guidance and resources through social support. Therefore, cognitive skills 
and emotions, particularly depressive symptoms, may have a relationship with social support, either individually or collectively, in the process of a choice.

\section{The Relationship Between Choice, Social Support, and Cognitive Skills}

Social support involves reciprocity and enables an individual to cope with stress and adapt to change (Jones \& Nystrom, 2012; Lindsey \& Yates, 2004; Masini \& Barrett, 2012). Individuals gain social support through interaction and development of relationships with others. These relationships offer the individual three distinct benefits: emotional, instrumental, and informational support (Ford, Tilley, \& McDonald, 1998a; Ford, Tilley, \& McDonald, 1998b). According to Ford et al. (1998a; 1998b), emotional support provides the individual with feelings of love, admiration, and respect. These feelings are often linked to relationships with family and friends and provided in two forms: instrumental and informational. Instrumental support enables the individual to use relationships to obtain a goal, whereas, informational support provides advice or information. Most individuals derive their social support from family and friends. This can also be a source of stress when desires or wishes are not mutually shared as when an older adult should retire from driving (Edwards et al., 2009; Freeman, Gange, Munoz, \& West, 2006; Mezuk \& Rebok, 2008). Other individuals look for support and guidance through more formal sources. When women faced choices for treatment of recurring ovarian cancer, they sought out a closer relationship with their oncologist and other health professionals (Elit et al., 2010). They made a choice to receive social support from persons they felt would provide the highest level of support. Often the individual looks to friends similar in age, experience, or lifestyles (Johnson, 1998), as well as 
individuals considered family without the biological link (Jones \& Nystrom, 2012; Masini \& Barrett, 2012).

When faced with the choice to retire from driving, older individuals reported both negative and positive feelings regarding social support (Croston et al., 2009; Friedland, Rudman, Chipman, \& Steen, 2006; Johnson, 1998; Odenheimer, 2006). Older individuals reported that when family members excluded them in the choice to retire from driving, i.e., the pre-retirement phase, they experienced feelings of losing control. This lack of involvement potentially affects the individual's sense of independence and quality of life (Gurland \& Gurland, 2009a; Gurland \& Gurland, 2009b). Often, older adults seek support from friends who are closer in age and are confronted with similar experiences (Johnson, 1998). Many older adults report friends offer greater understanding of the emotional impact of driving retirement than does family.

Driving retirement of the older adult is not without familial consequences. The loss of independence, once fulfilled by driving in the older adult, results in dependency upon others, particularly family. The additional burden of transportation upon family caregivers may lead to feelings of burden (Clark \& Diamond, 2010). Although not reported in the literature, intuitively this familial demand for informal transportation may result in financial burdens in time and/or additional care-related expenses. Thus, social support appears to affect the choice to retire or continue to drive but lacks clear empirical evidence. The relationship between social support and choice appears important, particularly when choices are multiple and emotion-laden. The literature identifies a relationship between emotions and social support. Furthermore, the literature 
also identifies a relationship between depressive symptoms and cognitive skills. When cognitive skills decline and begin to impact an individual's ability to make choices, a reliance on social support may occur. Therefore, it is possible the three factors have a collective impact on choice; the literature lacks clear empirical evidence. Figure 2 builds upon Figure 1 to further illustrate these potential relationships

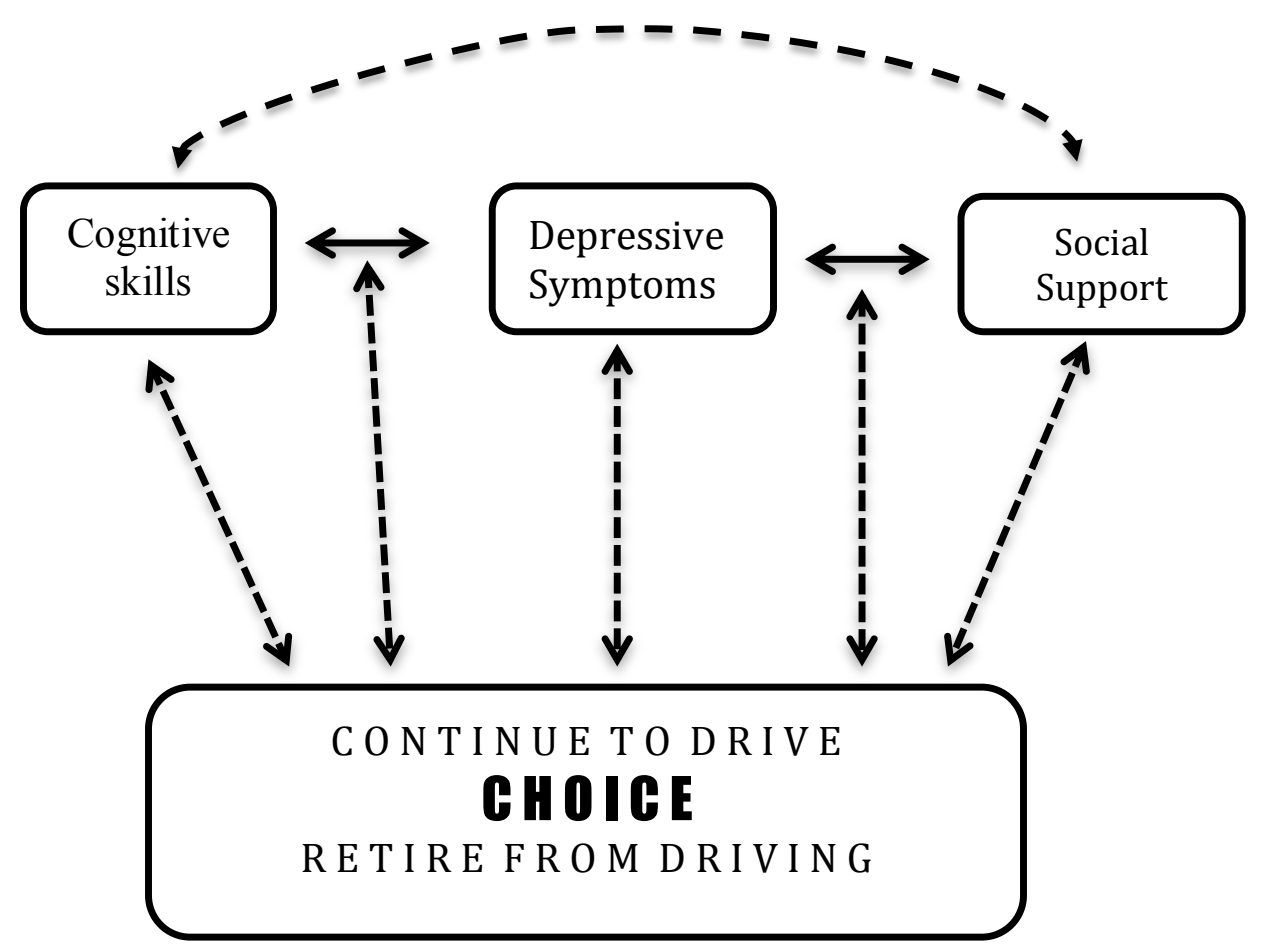

Figure 2. Building the CHOICE Framework

Building on Figure 1, the literature identifies a strong relationship between depressive symptoms and social support and is depicted as a solid bi-directional arrow between the two concepts. The literature remains unclear whether the individual concept of social support contributes to choice and is therefore depicted with a dotted bidirectional arrow between the concept and choice. The collective relationship between the two concepts of depressive symptoms and social support and choice remains unclear 
and is depicted by a dotted bi-directional arrow between the solid bi-directional arrow between the concepts and choice. Furthermore, the literature also suggests a relationship between social support and cognitive skills but remains unclear. Therefore, relationship between cognitive skills and social support is depicted with a dotted arrow between the concepts.

\section{The Relationship Between Choice and Functional Abilities}

Functional abilities are a "broad range of abilities that refer to the actual or potential capacity to perform the activities and tasks normally expected of an adult" (Richmond et al., 2004, p. 84). The aging process alone affects functional abilities over time irrespective of disease processes, particularly in the area of vision and overall muscle strength, thus affecting the individual's ability to perform everyday tasks, such as driving. Functional abilities specific to driving can be described as lower limb mobility, head-neck rotation necessary for visual scanning, and muscle strength, both upper and lower limbs (Baldock et al., 2006; Carr et al, 2006(b); Tuokko et al., 2007). The addition of disease processes both chronic, such as diabetes and cardiovascular disease (Bennett et al., 2010) and acute, such as hip fractures and cancer (Bower, 2008), may further impact functional abilities. Both types of illness have a potential impact on cognitive skills. Most of our cognitive processes receive input via sensory information, particularly visual. With aging, vision changes potentially affect cognitive skills negatively. Bower (2008) reported treatment modalities for cancer impacted cognitive skills in some individuals. This phenomenon is often labeled "cancer brain" and potentially impacts memory. 
Additionally, changes in functional abilities related to aging may be a determinant in the choice to retire from the workforce (Adams \& Beehr, 2003) or retire from driving (Colsher \& Wallace, 1993; D’Ambrosio et al., 2009). Individuals report reliance on their social support to assist in making choices when functional abilities decline. The individual may rely on their social support to assist in making choices in a three-prong approach: through the relationship between cognitive skills, emotions, and functional abilities. Therefore, the relationship between social supports may impact choice either directly or in combination with cognitive skills, emotions, or function abilities but the variation in relationships and the impact on choice remains unclear in the literature (see Figure 3). 


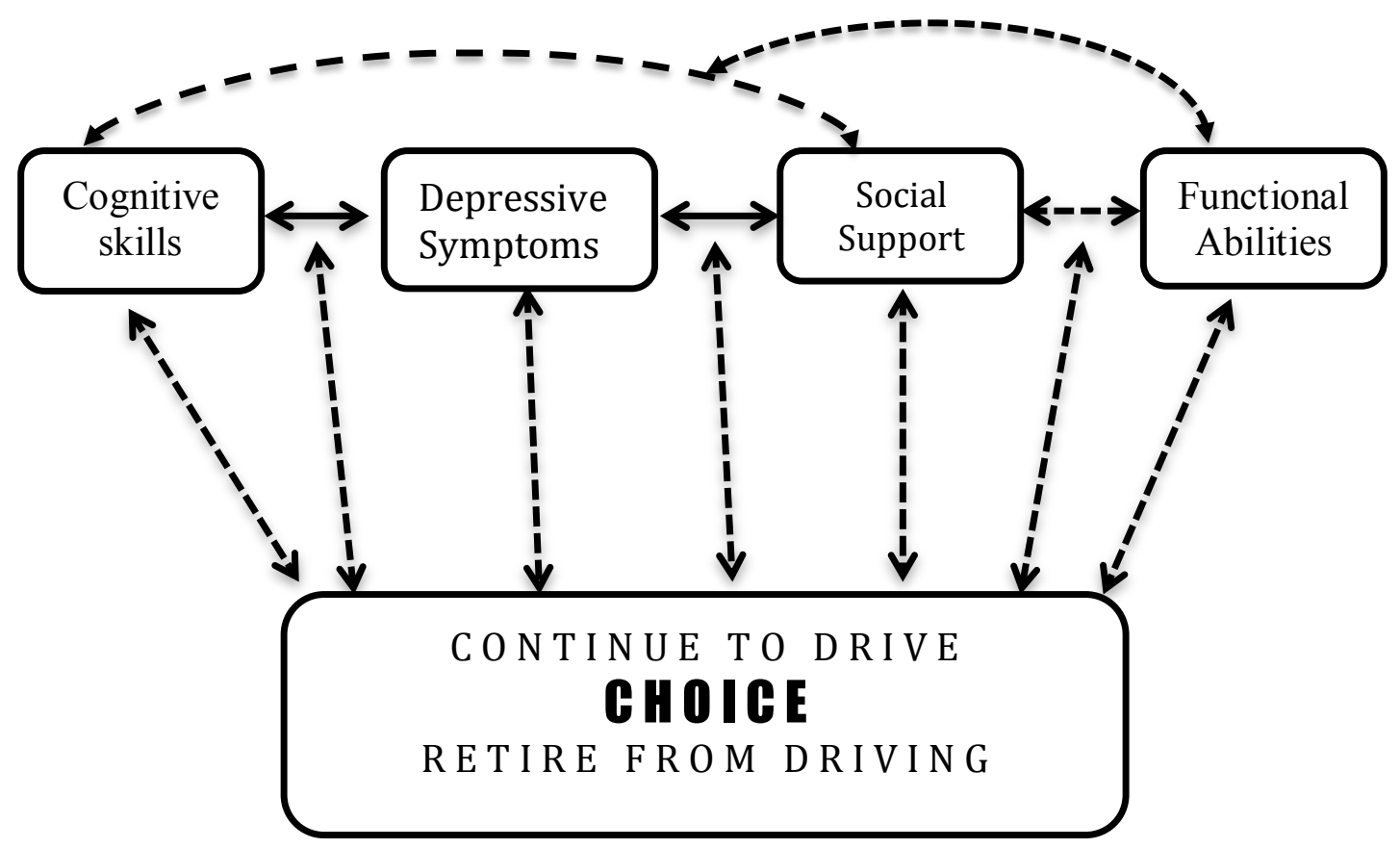

Figure 3. The CHOICE Framework.

Building on Figures 1 and 2, functional abilities have a relationship with social support, yet the relationship remains unclear. Therefore, this relationship is depicted by a dotted bi-directional arrow between the two concepts. The relationship between the two concepts and choice remains unclear and is therefore depicted by a dotted bi-directional arrow. The relationship between functional abilities and choice remains unclear and is depicted with a dotted bi-directional arrow. Additionally, the relationship between functional abilities, social support, and cognitive skills remains unclear and therefore are depicted with dotted arrows.

\section{The CHOICE Framework}

The review of literature indicates that cognitive skills, depressive symptoms, social support, and functional abilities impact an individual's ability to make choices, 
with some factors appearing to have a stronger relationship than others. Cognitive skills and depressive symptoms appear to have a bi-directional association, suggestive of a strong relationship. The presence of depressive symptoms appears to influence cognitive skills both in self-assessment and measurement. The Choice Framework depicts this relationship as a solid bi-directional arrow between the two concepts. Conversely, the relationship between these two concepts and their relationship to choice remains unclear and is therefore depicted as a dotted bi-directional arrow. The use of bi-directional arrows between concepts intuitively seems appropriate since the literature suggests a reciprocal relationship but remains unclear.

The literature suggests a relationship between depressive symptoms and social support. When an individual is confronted with a choice, the literature reports the emotional impact of the choice may be overwhelming for the individual and they turn to members of their social support (Edwards et al., 2009; Freeman et al., 2006; Mezuk \& Rebok, 2008). Both overwhelming emotional feelings and severity can potentially be expressed as depressive symptoms. Intuitively, the severity of depressive symptoms coincides not only with the overwhelming nature of choice but the ability to adapt to changes as Erikson (1982) describes in the developmental stage of ego-integrity versus despair. The literature suggests a strong relationship between the two concepts and is therefore depicted as a solid bi-directional arrow. The relationship between these two concepts and its relationship to choice remains unclear and is depicted as a dotted bidirectional arrow between the solid bi-directional arrow and the concept of choice. Intuitively, the common concept of depressive symptoms impacts cognitive skills and 
social support, thereby suggesting a relationship between all three, yet the literature remains unclear. In the Choice Framework, this relationship is depicted as a thin, solid, bi-directional arrow between the concepts depressive symptoms and social support, and social support and functional abilities. The literature remains inconclusive regarding these relationships and their relationship to choice. Therefore, a dotted bi-directional arrow depicts the relationship between the two concepts and its relationship to choice.

The relationship between the individual concepts of cognitive skills, depressive symptoms, social support, functional abilities, and choice remains unclear. The review of literature suggests that these four factors relate to one another either individually or collectively. Therefore, the relationship between individual concepts and choice are depicted with individual dotted bi-directional arrows between each concept and choice. The collective relationships are depicted in the Choice Framework as bi-directional arrows between cognitive skills, social support, depressive symptoms, and functional abilities. These relationships may be demonstrated in the choice to retire from driving by older adults, a life event that involves all four identified concepts but the literature remains unclear whether these concepts, either individually or collectively, impact the choice to retire from driving.

\section{Analytical Review of the Literature}

The integrative review of literature to this point has contributed to a general understanding of choice and the relationship of factors that contribute to an individual's ability to make choices. The analytical review of the literature provides a more in-depth analysis of studies by first providing an in-depth analysis of choice and concepts that 
contribute to the understanding of choice and then analyzing studies that place these concepts within the context of driving. This section of the literature provides a thorough understanding of the concept of choice and its potential relationship to driving retirement.

\section{Choice}

In addition to the general concepts related to choice, the potential relationships between these concepts have been identified and described in the literature. Baker (2006) explored choices made by individuals with Type 2 diabetes within the context of the economic rational choice framework of Hargreaves Heapes (as cited in Baker, 2006). Baker (2006) postulated that the utility of this framework might lead to a greater understanding of non-adherence to a prescribed medical regime. However, the economic framework of choice did not take into account the totality of the individual. Baker (2006) began by exploring the three identified components of this framework: instrumental rationality, procedural rationality, and expressive rationality. According to Baker (2006), instrumental rationality occurs when an individual making a choice attributes a subjective value to the choice rather than consequences of the choice. Procedural rationality involves the components of cognition and the role of social norms. Accordingly, procedural rationality, the association between cognition and choice, requires the individual to possess and utilize skills to weigh options that result in the best, or optimal, choice. Baker (2006) reported that individuals do not take either the initiative or time to process the appropriate or optimal choice thereby resulting in suboptimal choices. Within the context of health care, sub-optimal choices are those that 
contribute to the individual being labeled as non-adherent. The associated social norms within the defining characteristics of procedural rationality are often the result of habit. The final component of the economic rationality of choice is expressive rationality that involves the social and individual aspects of choice. The impact of social and individual aspects of choice is unclear but intuitively considered important.

To better understand this framework, Baker (2006) studied individuals with diabetes mellitus. This study consisted of 27 participants in the United Kingdom ranging in age from 30 to over 70 years. Using the $Q$ methodology, which is a mixed-method design, Baker (2006) identified 46 factors that individuals reporting their management of diabetes. Placing this identified factors or statements on individual cards the participants used the ' $Q$ ' sort or sorted the cards according to their personal experience of managing their disease process. Each participant sorted the factors according to "This factor strongly applies to me" to "This factor strongly does not apply to me" (Baker, 2006) Using factor analysis of each Q sort, three factors emerged: responsibility for future health, a holistic view of health and lifestyle, and the good patient (Baker, 2006). Responsibility for future health was negatively associated with improved knowledge with better control of the disease process and reduced hospitalizations (cognitive skills). Individuals expressed lack of control over the disease and looked more at the immediate consequences of the disease and not the future or long-term effects of the disease. When individuals express feelings of lack of control, depressive symptoms may arise. Finally, the 'good patient' theme involved the associated need to deviate from acceptable health choices to maintain social normality (Baker, 2006). Therefore, these identified factors in 
this study contributes to the potential relationship between choice, depressive symptoms, and cognitive skills.

Using a sample of 14 older adults with a diagnosis of end-stage renal failure, Visser and colleagues (2009) explored why some older adults choose dialysis (Group $1=$ dialysis; Group 2 = no dialysis). Although only eight participants (Group 1) started dialysis, both groups indicated that dialysis limited their overall autonomy. The lack of autonomy was the predominant theme for those who did not start dialysis (Group 2; n = 6). Quality of life was another theme shared by the two groups. Group 1 was more optimistic about their quality of life than Group 2. Optimism reflected the potential for organ transplantation and prolonging life. In addition, optimism related to a social consideration since one member of Group 1 chose dialysis because of the role of primary caregiver for an ill partner or child. These results suggest that social support or social obligations play an important role in making a choice. All participants were considered cognitively intact and therefore relied on the ability to weigh risk versus benefits within the context of individual values of autonomy (independence) and quality of life. These values are similar to those associated with the choice to retire from driving.

Using a sample of 18 older adults contemplating total hip arthroplasty (THA), Donsanjih, Matta, and Bhandari (2009) explored how the individuals arrived at the decision for the surgery. The three over-arching themes that emerged were physical limitations, psychological distress, and perceptions of hip arthroplasty. Specifically, functional ability to perform activities of daily living and social activities played a primary role in the choice to have a THA. As functional abilities decline, individuals 
reported greater satisfaction with the choice for a THA. Various emotions played a role in the THA choice such as depressive symptoms, perceptions of body image, and fear. Furthermore, satisfaction with the THA choice resulted from both cognition and social support. Cognitive skills enabled the participants to actively engage in choosing a surgeon and the surgical procedure. Participants consulted with individuals who had prior THA through face-to-face conversations and use of the Internet. Through these social support efforts, participants gained more knowledge about the procedures, the surgeons, and the impact on quality of life. Social support, both formal and informal also contributed to choosing the surgeon and procedure by offering emotional support and advice. This study further supports the relationship between choice, functional abilities, social support, and emotions.

Finally, Henwood and colleagues (2011) explored the everyday 'healthy living' practices of 44 adults ranging in age from 45 to 70 years, who resided in the United Kingdom. Three themes emerged emphasizing two major ideas: (1) cognition such as understanding information is important, but alone means nothing, and (2) in the absence of social support, individuals report feelings of anxiety and stress, often expressions of depressive symptoms. This study illustrated that in the absence of formal support, i.e. health care providers, individuals sought support from informal sources, such as family and friends, to assist them with understanding so they could make choices. This study further supports the relationship between cognitive skills, depressive symptoms, and social support. 
The analysis of these studies indicates individuals use cognitive skills, depressive symptoms, social support, and functional abilities to make choices. It is evident that choice is impacted by these four factors individually and collectively, although choice has been historically seen as a singular process. The combination of factors appears to relate to the conceptual nature of the choice, but within the context of driving, this concept lacks clarity. Therefore, it is critical to analyze studies that indicated perhaps the meaning of the relationship of these factors to the choice to retire from driving.

\section{Choice and Driving Retirement}

The driving literature indicates choice and driving in older adults have similar themes and concepts. Four distinct factors, cognitive skills, depressive symptoms, social support, and functional abilities, appear inter-related when discussing choice within the context of driving in older adults.

Johnson (1998) explored the influence of family and friends of rural older adults $(\mathrm{N}=60$; age $=71-98)$ in their decision to retire from driving. Although the participants identified their daughter or granddaughter as the most influential family member, these family members often lived away and could not relate to their situation. The participants were more inclined to talk with their friends, stating, "they understood" their situation. Participants reported they respected their friends' evaluation of their driving skills more often than family members' evaluations (Johnson, 1998).

Along with identification of influential members of their social support, six themes emerged and these included trust, support, acceptance, anger, sorrow, and loneliness (Johnson, 1998). Participants reported once the decision to retire from driving was made, there was a need to grieve their loss of independence. This reported need to 
grieve indicates that driving retirement involves emotions the participants identified as anger, sorrow, and loneliness. The expression and the potential for unresolved feelings infer the possible development of depressive symptoms. This study provides insight into the importance of social support and the potential presence of depressive symptoms resulting from the loss of independence associated with driving retirement.

Donorfio and colleagues (2009) explored self-regulatory driving behaviors in older adults participating in nine focus groups. Of the six identified themes, the first theme related to functional abilities. Participants were "very aware" (p. 329) of physical change or functional abilities that influenced their driving. Most common physical changes identified were vision, hearing, reflexes, and neck/shoulder mobility. This reported awareness or cognition of their declining functional abilities had associated emotions, which is the second identified theme. Individuals reported a lack of confidence in their driving ability, expressed less enjoyment when driving, decreased ability to concentrate, lack of trust in other drivers, and decreased ability to handle stressful driving situations. These emotions brought an awareness or cognition to the individual that, although their functional ability to drive was declining, the desire to continue driving remained. The third theme related to the type of self-regulation strategies used to retain their ability to drive yet limit their overall driving. Participants reported driving closer to home or only for important activities (e.g., church, social activities, or groceries). They no longer drove at night or in inclement weather. Theme four described how driving connected people "to life"; the underlying message was driving enabled them to retain their independence. An individual reported "I would even 
go to yoga if people said you had to for driving" (p.332). This study indicates declining functional abilities and the associated cognitive awareness of their abilities to driving independence outweighed their abilities leading to a conscious choice to continue to drive. The participants considered driving a fundamental part of their life. The fifth theme related to locus of control and gender differences. For men, driving is an extrinsic event that is outside their ability to control the driving of others or the environment. For women, driving is an intrinsic event where they had the ability to control their driving behavior. In addition, women had or were willing to enroll in a defensive driving course to retain their ability to drive. Finally, the sixth theme related to dissatisfaction with transportation alternatives. Participants reported the alternatives as inconvenient, inflexible, and unavailable. This study clearly indicated that the choice to drive is associated with cognitive skills and functional abilities. The results again associate driving with independence. Potentially, the loss of independence and the expressions of driving as a fundamental part of life could lead to the development of depressive symptoms, ultimately impacting choice.

Bauer, Rottunda, and Adler (2003) explored the lived experience of driving cessation in six older Caucasian women with a median time for driving retirement of 100.5 days. Of the six participants, four participants chose to retire from driving. Four participants reported declining functional abilities, such as macular degeneration, hearing impairment, and sequaele of chronic illnesses, impacted their choice. These participants also reported that continued driving caused anxiety. Their conscious awareness of their declining functional abilities and the associated emotions enabled 
them to voluntarily choose to retire from driving (Bauer et al., 2003). Conversely, the two remaining participants reported driving retirement was an involuntary choice. Both women reported members in their social support "forced" driving retirement upon them and reported emotions such as anger and resentment. With both women, the family either sold their car or hid their keys to cease their driving (Bauer et al., 2003). It is interesting to note that all six women, whether the choice was voluntary or involuntary, associated driving with self-worth. Their lives now lack the spontaneity driving provided. This study offers additional support that the choice to drive is associated with cognitive skills, depressive symptoms, social support and functional abilities. The relationships between these four factors either individually or collectively impact the independence and self-worth of the older adult driver and retirement from driving (Bauer et al., 2003).

Johnson (2002) explored why some older drivers continued to drive after being informed their driving was no longer safe. All 45 participants lived in their own homes, were cognitively intact, and were still driving. The majority of the drivers were advised to stop driving by a family member such as a daughter or daughter-in-law (47\%) versus a professional such as a nurse practitioner $(13 \%)$ or a physician $(11 \%)$. They were advised to stop driving due to declining health or functional abilities, such as hearing, vision, or mobility, but they chose to continue to drive (Johnson, 2002). This study indicates a disparity between the participants' perceived driving abilities and their social support views of driving abilities even when the participants acknowledged they had "a few mishaps." The disparate views often left the participants feeling frustrated. One woman reported: 
I have trouble seeing with my glasses and I wear an aid in both ears. My daughter insists that I shouldn't be driving just because of that. But you know what? The couple accidents I've had weren't that serious, so I don't think my bad eyes and ears had much to do with 'em. I just have to get her to understand that! (Woman, age 82 , Johnson, 2002, p. 240)

Participants reported that not driving limited their independence and forced their reliance on others. One participant stated:

No driving? That's not even a reasonable choice. What would happen to me? How would I get food, medicine, see the doc, go to church? No, I'm afraid to have to depend on anyone but me. I'd probably just get very sad and blue, maybe even senile (Johnson, 2002, p. 241).

Interestingly, several participants stated that a "test of some sort" to indicate unsafe driving skills might help them make the choice to retire from driving. This study indicates a relationship between cognitive skills, depressive symptoms, social support, and functional abilities, and the impact on the older adult's choice to continue to drive. Although the older adult had an awareness of poor driving skills, the emotions associated with independence and driving were the overriding factor for the continuation of driving.

Johnson (2008) did a follow-up study based on the previous findings of the relationship between social support, functional abilities, and driving. Where the previous study focused on the continuation of driving, this study focused on the long-term effect of social support and driving retirement. In this study, older women voluntarily chose to 
cease driving primarily related to a decline in functional abilities. All participants reported living alone made them feel isolated, scared, and unable to survive. Forty-eight per cent of the participants resumed driving due to lack of social support. They were aware of their unsafe driving, but the alternative was not acceptable. Conversely, the women who continued driving expressed feelings of value and support. They had daily contact with family and friends by telephone, e-mail, or frequent visits. Interestingly, the women who continued driving reported minimal contact with either family or friends. The study showed that social support and emotions have a direct relationship with the choice to retire from driving.

The analytical review of the literature indicates within the process of choice, relationships exist between four factors: cognitive skills, depressive symptoms, social support, and functional abilities on choice. Placing these factors within the context of driving retirement, these four factors conceptually define how older adults respond, react, and/or deal with choices involving driving. Although none of the studies explicitly identified depressive symptoms, the individual expressions of loss, lack of control, and fear are the essence of the conceptual definition. Yet the relationships between these four identified factors, either individually or collectively, and within the context of choice remain unclear and un-examined in research 


\section{Significance to Gerontological Research}

Exploring factors that influence choice offers a conceptual understanding of choice both in general and specifically within the context of driving retirement. The review of literature revealed that cognitive skills, depressive symptoms, social support, and functional abilities impact choice either individually or collectively but the relationships remain unclear. Studying these factors, their relationships, and their impact.on choice may provide an opportunity to address this problem and the potential to offer a richer understanding of both driving retirement and the challenges faced by older adults when confronted with this dilemma. This study would be the first to address driving retirement in the context of choice, thus making this study innovative and original.

This study offers a new approach in researching this public health concern in both gerontology and public health. The results may offer different avenues for assessment as well as an appreciation of older adult drivers, ultimately leading to enhanced health care. The next chapter outlines a research study to investigate the relationship of the identified factors on the choice to retire from driving. 


\section{CHAPTER III}

\section{METHODS}

This chapter provides the information necessary to conduct a successful research study. Recruitment strategies, data collection tools and procedures, and data analysis procedures provide a clear description of the proposed research study.

\section{Elements of Research Study}

\section{Design}

This descriptive, retrospective, cross-sectional study, was designed to explore the relationship between the four identified factors related to choice on driving retirement in adults aged 60 and older, living in the community.

\section{Sample}

A convenience sample of adults, age 60 and older and living in the community, was used. A power analysis for logistic regression was conducted using G*power 3.1. The analysis yielded a sample size of 238 to achieve a power of 0.95 . Inclusion criteria were (1) adults age 60 years and older; (2) living in the community, either independently, in assisted living, or with family; (3) who were able to read and understand English; or (4) were either drivers; or (5) non-drivers. Exclusion criteria were individuals residing in a nursing home; had a cognitive impairment resulting from head injury or Parkinson's disease, or were legally blind. 


\section{Setting}

Psychology Specialists, LTD is a community-based organization with its main headquarters located in Bloomington, Illinois. The organization employs neuropsychologists, licensed social workers, licensed clinical professional counselors, and support staff. Psychology services are offered in 11 settings throughout central Illinois. Services at each clinic differ, specializing in services ranging from the psychological effects of chronic pain, to marriage counseling, to neuropsychological assessments. The Decatur location is the only clinic offering neuropsychological testing.

The Decatur office is located at 102 W. Kenwood, Suite 120A, on the campus of Decatur Memorial Hospital. The Decatur office provides psychology services to individuals from physician referrals (90\%), insurance companies $(5 \%)$, and community or individual referrals $(5 \%)$. The Decatur office has a staff of neuropsychologists, licensed social workers, licensed clinical professional counselors, and secretarial services. The primary neuropsychologist has a current caseload of 700 individuals, which includes 250 new referrals annually. On a daily basis, he averages a caseload of 10 individuals requiring neuropsychological testing or follow-up.

\section{Procedure}

A convenience sample of 151 were selected from a total of 500 active charts of patients who met the inclusion criteria and had been treated at the office of Psychology Specialists, LTD, 102 W. Kenwood, Suite 120A, Decatur, Illinois. Data necessary for answering the research questions were found in the narrative report of testing in each individual client's chart. The administrative assistant at Psychology Specialists, LTD 
under the supervision of the neuropsychologist selected charts that met the identified inclusion criteria. Once the chart was selected, the administrative assistant made a photocopy of the narrative report that included the quantitative results of the cognitive testing, depressive symptom scores, and functional abilities. The administrative assistant redacted any identifying information listed under Methods for De-identification of Protected Health Information in Accordance with the Health Insurance Portability and Accountability Act (HIPAA) Privacy Rule; specifically, the information found in these medical records which needed to be redacted prior to study included name, date of birth, social security number, chart identification number, health insurance information, telephone number, personal address, admission date to Psychology Specialists, LTD, date of testing by the primary neuropsychologist, and zip code. After redacting the personal identifiers, the administrative assistant again photocopying the page to ensure that no personal identifying information was visible to the PI and co-PI's. The administrative assistant then wrote on the top of the final copy the gender, age in years (except individuals older than 89 years of age were written as $90+$ years as required under Methods for De-identification of Protected Health Information in Accordance with the Health Insurance Portability and Accountability Act (HIPAA) Privacy Rule), and driving status of the participant. Prior to the co-PI receiving the redacted chart copies, the primary neuropsychologist reviewed the copies to ensure that all personal identifying information has been appropriately redacted and the information necessary for the study was complete. At no time did the co-PI (DJJ) have access to the medical records or record storage system at the office of Psychology Specialists, LTD. Once the redacted 
information was received, the information was entered into the co- PI's (DJJ) password protected computer utilizing the ISU campus datacenter.

\section{Protection of Human Subjects}

Protection of human subjects and their information was accomplished in several ways. First, the Institutional Review Board (IRB) at Illinois State University approved the study. As part of the Institutional Review Board protocol, a signed Confidentiality Agreement with Psychology Specialists, LTD was signed by the co-PI (Refer to Appendix A). Psychology Specialists, LTD is a community-based organization that does not have an IRB. This form provides assurance that participant information remains confidential and ensures HIPPA regulations are maintained.

The PI and co-PI's had access to copies of redacted chart information that includes demographic information limited to age in years, marital status, and gender, quantitative or numerical results of neuropsychological tests for cognition, hand-grip strength, use of assistive devices for mobility, and driving status. Following receipt of the information, the data was entered into the virtual and physical servers at Illinois State University (ISU). Mennonite College of Nursing at ISU utilizes the campus datacenter infrastructure to provide a secure location for data, access to redundant and emergency power, and suitable environment services like cooling. MCN maintains both virtual and physical servers in within these spaces capable of offering storage, backup, and, when necessary, encryption of data.

Sensitive or protected research data can be placed on servers with minimal or no access to the Internet where it can also be protected via system and user permissions. 
For extra security, the data were encrypted so that only designated users could access it. All access was logged in order to provide audits of access to the data should they become necessary. When data is no longer required it will be securely erased via software that over-writes files with random data several times. Within 30 days of being erased the data will automatically be over-written in the backup system, making it impossible to recover. The data extraction and storage procedures ensured minimal risk of harm to the participants. 


\section{Instruments/Measurements}

The variables in this study and instruments used to measure them are described in this section. A summary of this information is found in Table I.

Table 1

Study Variables and Instruments/Measurements

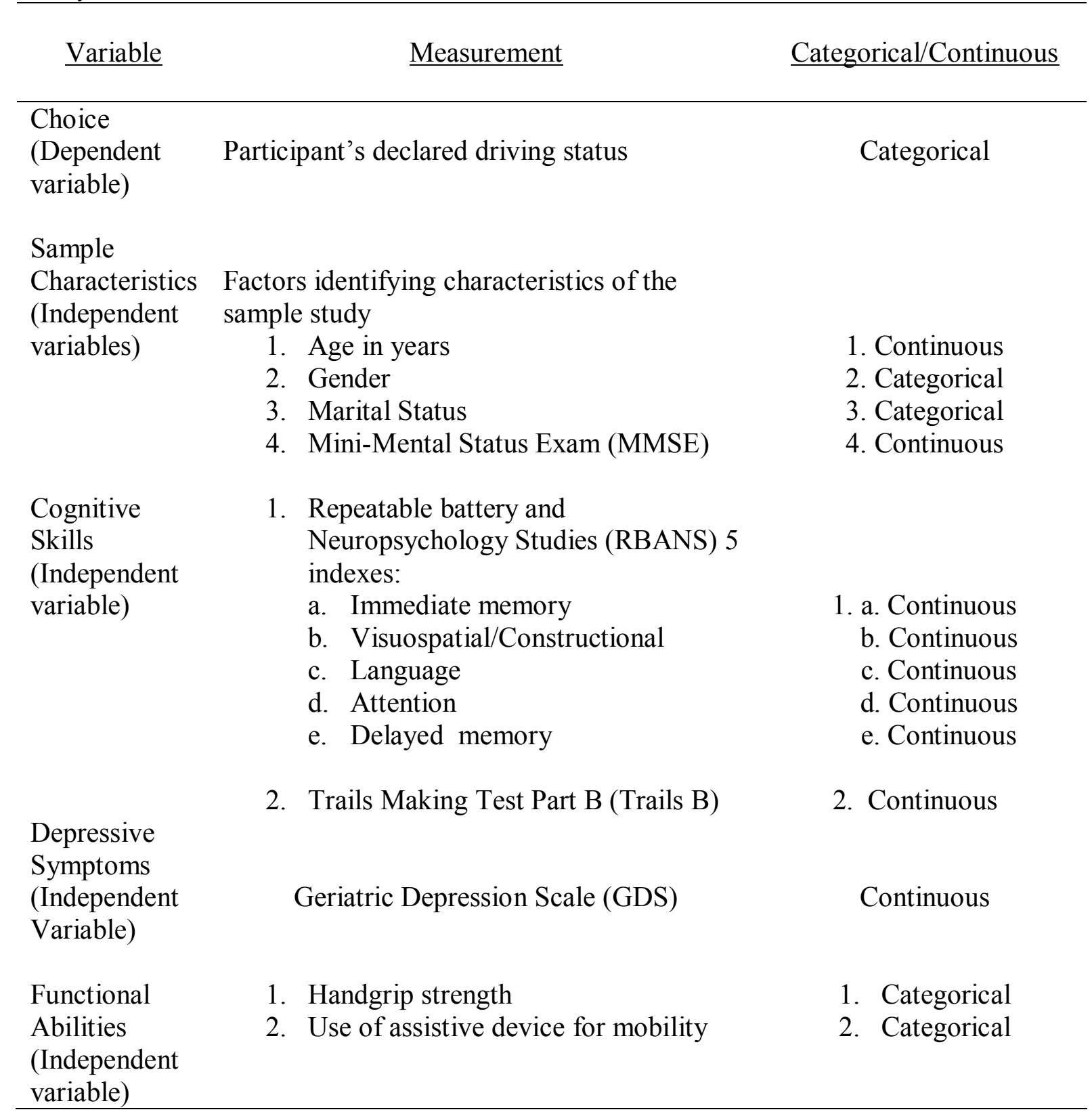




\section{Explanation of Instruments/Measurements}

Choice. Choice was operationally defined as the declared driving status as recorded in the participant's chart. This information identified the individual's choice to either retire or continue driving. This was measured as either yes/driving or no/not driving, and therefore was a categorical variable.

Sample characteristics. Sample characteristics provide an overall description of the participants. It was necessary to operationally define two of the four variables. For the purpose of this study, older adults were operationally defined as adults age 60 years and older. This variable was measured as age in years and is a continuous variable. The second variable was the Mini-Mental Status Examination (MMSE). Operationally, this screening tool provided a general description of each participant's cognitive status (Folstein, Folstein, \& McHugh, 1975). The MMSE uses 30 questions to obtain cognitive skills within five domains: orientation, immediate memory, attention, language, and recall. Scores range from 0 to 30 with higher scores indicating minimal to no cognitive skill impairment. The specificity and sensitivity are .90 and .69 respectively. This variable is continuous.

Cognitive skills. The operational definition of cognitive skills required documentation of subtle or discrete measurement of cognitive skills.

a. The measurement of cognitive skills was scores obtained using the Repeatable Battery for the Assessment of Neuropsychological Status (RBANS) (Randolph, Tierney, Mohr, \& Chase, 1998). Although not a diagnostic tool, this test provided a baseline of cognitive function and the 
ability to repeat measurements necessary for supporting the diagnosis of cognitive impairment usually indicative of Alzheimer's disease. The RBANS consists of five indexes with each index consisting of two to four subtests for a total of 12 subtests. Each subtest includes a combination of tests that provides an in-depth measurement of one index, such as immediate memory. Each index has a mean score of 100 with an overall standard deviation of \pm 10 . Within each index, a lower score equates to severity of cognitive deficiency. Adjusted scores are available for differences in age and education, making this a more inclusive tool for measurement of cognitive functioning for older adults. (Duff et al., 2005; Duff et al., 2009). The RBANS has good internal consistency for each index: Immediate memory $=$ $.96 ;$ Visuospatial $/$ Constructional $=.74 ;$ Language $=.83 ;$ Attention $=.81 ;$ Delayed Memory $=.98$ (Duff et al, 2005). Each index score is a continuous variable. Table 2 provides each index, the subtests that combine to make each index, and a brief description of each subtest. 
Table 2

RBANS Indexes with Associated Subtests

\begin{tabular}{|c|c|c|}
\hline \multirow{3}{*}{$\begin{array}{l}\text { RBANS index } \\
\text { Immediate Memory }\end{array}$} & RBANS Subtest & Description of subtest \\
\hline & a. List learning & $\begin{array}{l}\text { a. Individual listens to a list of } \\
\text { words and then is asked to } \\
\text { repeat back the list within a } \\
\text { set time. }\end{array}$ \\
\hline & b. Story Memory & $\begin{array}{l}\text { b. Individual listens to a story } \\
\text { and then repeats the story } \\
\text { back with a set time. }\end{array}$ \\
\hline
\end{tabular}

\begin{tabular}{|c|c|c|}
\hline \multirow[t]{2}{*}{ Visuospatial/Constructional } & a. Figure copy & $\begin{array}{l}\text { a. Individual draws a copy of a } \\
\text { figure within view }\end{array}$ \\
\hline & b. Line orientation & $\begin{array}{l}\text { b. Individual has ten angles to } \\
\text { describe the direction and } \\
\text { "degree" of angle. }\end{array}$ \\
\hline Language & b. Semantic fluency & $\begin{array}{l}\text { a. The evaluator provides } \\
\text { pictures of common items } \\
\text { one at a time, such as apple, } \\
\text { hammer, etc. } \\
\text { b. Individual is asked to name } \\
\text { as many fruits within a set } \\
\text { time. }\end{array}$ \\
\hline Attention & a. Digit span & $\begin{array}{l}\text { a. Individual is given a list of } \\
\text { numbers starting with a } \\
\text { small sequence, increasing } \\
\text { in length until the list of } \\
\text { numbers is } 9 \text { in length } \\
\text { b. Individual must fill in } \\
\text { numbers on a sheet of paper } \\
\text { corresponding to shapes } \\
\text { with a set time }\end{array}$ \\
\hline Delayed Memory & $\begin{array}{l}\text { c. Story recall } \\
\text { d. Figure recall }\end{array}$ & $\begin{array}{l}\text { a. Individual asked to repeat } \\
\text { the list of words that were in } \\
\text { the original list at the } \\
\text { beginning of test. } \\
\text { b. Again, the individual is to } \\
\text { identify if a word the } \\
\text { evaluator provides was in } \\
\text { the original list but this time } \\
\text { the evaluator includes ten } \\
\text { words that were not in the } \\
\text { original list. } \\
\text { c. Individual repeats the } \\
\text { original story. } \\
\text { d. Individual is asked to draw } \\
\text { the original figure from } \\
\text { memory. }\end{array}$ \\
\hline
\end{tabular}


b. The measurement of a participant's ability to remain attentive, switch tasks or mental flexibility, and scan the area or environment is additional cognitive skills that are important for safe driving (Staplin, Gish, \& Sifrit, 2014). Although the RBANS measures these tasks, the Trails Making Test (TMT) Part B (Lezak, et al., 2004) offers more definitive measurements of these abilities. Part B requires the individual to switch from numbers to letters and back to numbers in sequence. The individual starts with the number one followed by finding the letter "A" then finding number two and so on in order. This is a timed test with maximum allotted time of five minutes. Scoring is based on accuracy and completion time (Ashendorf et al., 2008; Sanchez-Cubillo et al, 2009). The TMT has an average reliability co-efficient of .80 (Lezak et al., 2004).

Depressive symptoms. The presence of depressive symptoms in individuals receiving cognitive testing can yield inaccurate results. Individuals with depressive symptoms may minimize their effort to perform the test at their maximum ability. Depressive symptoms were operationally defined as scores obtained from the Geriatric Depressive Scale (GDS) (Yesavage et al., 1983). The GDS is a 30-item questionnaire that screens for the presence of depressive symptoms specific to the older population. Participants are asked to score each item as yes or no. Scores can range from 0 , indicative of no depressive symptoms, to 30 , indicative of severe depressive symptoms. It has $92 \%$ sensitivity and $89 \%$ specificity for the presence of depressive symptoms. A moderate to high score (a score greater than ten) may require diagnostic testing. This score is a continuous variable. 
Functional abilities. The operational definition of functional abilities included measurement of handgrip strength and the participant's use of assistive devices (Bohannon, 2008; Sallinen et al., 2010). Handgrip strength is measured using a dynamometer in both dominant and non-dominant hands with the participant's arm flexed at $90^{\circ}$ and positioned at waist level. The participant is instructed to squeeze the dynamometer "as hard as possible" for 3 to 5 seconds. The participant performs the task generally three times with a 30 second rest recovery period between tasks. The average of the three measurements is recorded in kilograms $(\mathrm{kg})$. Handgrip scores vary with age and gender. Overall handgrip strength scores of $37 \mathrm{~kg}$ in males (sensitivity $62 \%$ and specificity $76 \%$ ) and $21 \mathrm{~kg}$ in females (sensitivity $67 \%$ and specificity $73 \%$ ) or greater suggest greater functional ability. Scores suggesting risk for limited functional abilities are less than $33 \mathrm{~kg}$ in men (sensitivity $73 \%$ and specificity $79 \%$ ) and less than $20 \mathrm{~kg}$ women (sensitivity $74 \%$ and specificity $72 \%$ ) (Sallinen et al., 2010). The score is a categorical variable.

Additionally, the participant's use of assistive devices for mobility, such as quadcane or walker, provided insight related to either balance or lower body strength. While not conclusive for either measurement, the use of assistive devices provides more information regarding the participant's ability to function within their environment. Operationally, this was measured as yes/participant uses an assistive device or no/participant does not use an assistive device for mobility. This measurement is a categorical variable. 


\section{Analysis of the Data}

Prior to commencement of data collection, the SPSS (v. 21) data editor was constructed with all variables identified and coded. Data cleansing was used to identify missing, duplicate, or incomplete data.

Research Question 1: What are the characteristics of older adult drivers residing in the community that choose to retire from driving or continue to drive?

Characterization of the sample with the collected data was completed with the descriptive statistics of mean, standard deviation, frequency, and range for continuous variables and frequencies as well as percentages for categorical variables.

Research Question 2: What is the relationship between the four variables (cognitive skills, depressive symptoms, social support, and functional abilities) that are most influential in the choice to retire from driving? The point biserial correlation was computed for the relationship between continuous independent variables and a dependent variable of the choice to retire from driving and $\chi^{2}$ test for the relationship between categorical independent variables and the dependent variable of the choice to retire from driving. All significance level was reported at $p \leq .05$.

Research Question 3: What are the predictors of choice to retire from driving or continue to drive? Univariate and multivariate logistic regression was conducted to identify predictive variables of choice to retire from driving or continue to drive. The independent variables included age, the five index scores of the RBANS, Total RBAN score, GDS, and Trails B. Variables that show significances $(\mathrm{p} \leq .10)$ in the univariate analysis were entered in the multivariate logistic regression backward stepwise model to 
determine those that were independently related to the dependent variable of choice to retire from driving or continue to drive. All statistical significance was reported at $p$ $\leq .05$.

This chapter has outlined all the details necessary to perform a research study that protects human subjects. The methods of data collection and analysis provide a clear, concise discussion to potentially answer the identified research questions. 


\section{CHAPTER IV}

\section{RESULTS}

The results of data analysis are presented in this chapter in sections. These sections include sample characteristics, followed by multivariate analysis of sample characteristics and key variables, and end with analysis of data to answer the research questions posed in chapter one. This chapter provides the results of the study, highlighting significant findings that will be discussed in-depth in Chapter 5.

\section{Descriptive Analyses}

\section{Description of the Sample}

The final sample size was 151: 55 non-drivers (36\%) and 96 drivers (64\%). The final sample of 151 equates to $21.5 \%$ of the neuropsychologists caseload of 700 . The most significant factor that affected the final sample was age with ages ranging from early 20 's to over 90 . The second factor that affected sample size was inclusion criteria. Individuals with a diagnosis of Parkinson's disease, cerebral vascular accident and head injury did not meet criteria for the study. The final sample reduced the power from .95 to .74. Although lower, a power of .74 remains within the parameters of a statistically significant study. In this sample, non-drivers tended to be female $(69.6 \%)$ and older $(M=$ 80.7 years, $S D=7.5)$, whereas, drivers tended to be male $(55.1 \%)$ and younger 
$(M=74.5$ years, $S D=7.3)$. Non-drivers were more likely to be unmarried $(58.1 \%)$ versus drivers (70.8\%). Table 3 presents a detailed description of the sample.

Table 3

Demographic Characteristics of the Sample

\begin{tabular}{lcc}
\hline & Non-drivers $(n=55)$ & Drivers $(n=96)$ \\
$n(\%)$ & $n(\%)$ \\
\hline Age: & & $25(26.0)$ \\
$60-69$ & $6(10.9)$ & $40(41.7)$ \\
$70-79$ & $15(27.3)$ & $30(31.3)$ \\
$90+89$ & $28(50.9)$ & $1(1.0)$ \\
Gender: & $6(10.9)$ & \\
Male & & $46(51.1)$ \\
Female & $17(30.9)$ & $43(44.8)$ \\
Marital Status: & $38(69.1)$ & \\
Single (Never married) & & $1(1.0)$ \\
Married & $1(1.8)$ & $68(70.8)$ \\
Divorced & $23(41.8)$ & $5(5.2)$ \\
Widowed & $7(12.7)$ & $22(22.9)$ \\
& $24(43.6)$ & \\
MMSE: & & $52(54.2)$ \\
Normal & $17(30.9)$ & $20(20.8)$ \\
Mildly impaired & $23(41.8)$ & $17(17.7)$ \\
Moderately impaired & $9(16.8)$ & $7(7.3)$ \\
Severely impaired & $6(10.9)$ & \\
& & \\
\hline
\end{tabular}

\section{Description of Cognitive Status}

The MMSE indicated that non-drivers $(M=24.6, S D=3.7)$ and drivers $(M=$ 25.8, $S D=3.4$ ) were mildly cognitively impaired. Both groups had a similar range of scores on the MMSE; non-drivers' scores ranged from 15 to 29 and drivers' scores ranged from 14 to 30 . The mean scores of all RBANS indexes for both groups fell below the instrument's normed average of 100 , which demonstrates specific areas of cognitive 
impairment versus a general classification of cognitive impairment ranging from mild to severe. Whereas the MMSE classified both groups as having mild cognitive impairment, the RBANS showed impairment specifically in the index scores of immediate memory, visuospatial, and delayed memory (see Table 4).

Table 4

Means, Standard Deviations, and Ranges for each RBANS Index

Non-Driver $\quad$ Driver

\begin{tabular}{lllll}
\cline { 2 - 4 } Immediate Memory & $M(S D)$ & Range* & $M(\mathrm{SD})$ & Range* \\
\cline { 2 - 4 } Visuospatial & $78.8(14.6)$ & $40-106$ & $80.4(21.1)$ & $40-120$ \\
Language & $78.8(15.9)$ & $50-116$ & $87.4(17.0)$ & $56-126$ \\
Attention & $83.5(14.6)$ & $44-108$ & $89.7(13.2)$ & $40-120$ \\
Delayed Memory & $61.9(14.9)$ & $56-128$ & $89.2(10.4)$ & $49-135$ \\
Total RBANS & $70.3(12.5)$ & $47-94$ & $80.3(17.8)$ & $45-119$
\end{tabular}

\footnotetext{
*Scores of 55 or less indicate severe cognitive impairment
}

Non-drivers had moderate to severe deficiencies in all indexes of the RBANS with the exception of two non-drivers categorized as having average or below average cognition (Table 5). The Total RBANS score for non-drivers clearly demonstrates the severity of their cognitive deficiencies with a combined $78.2 \%$ categorized as moderate to severely deficient. The Total RBANS score for drivers demonstrates this group also had severe cognitive deficiencies with $46.9 \%$ categorized with moderate to severe cognitive deficiencies; however, these deficiencies occurred at a lower frequency than among the non-drivers. Drivers achieved higher Total RBANS scores with 31.2\% 
categorized as average to superior cognitive skills (Table 6). The RBANS indexes

indicate non-drivers had more pronounced deficiencies in the areas of immediate

memory, delayed memory, and visuospatial compared to drivers, who had deficiencies

in both immediate and delayed memory.

Table 5

Frequencies and Percentages by RBANS Indexes for Non-Drivers $(n=55)$

\begin{tabular}{|c|c|c|c|c|c|c|}
\hline & $\begin{array}{l}\text { Immediate } \\
\text { Memory } \\
\mathrm{n}(\%)\end{array}$ & $\begin{array}{l}\text { Visuospatial/ } \\
\text { Constructional } \\
\text { n (\%) }\end{array}$ & $\begin{array}{l}\text { Language } \\
\mathrm{n}(\%)\end{array}$ & $\begin{array}{l}\text { Attention } \\
\mathrm{n}(\%)\end{array}$ & $\begin{array}{l}\text { Delayed } \\
\text { Memory } \\
\mathrm{n}(\%)\end{array}$ & $\begin{array}{l}\text { Total } \\
\text { Score } \\
\mathrm{n}(\%)\end{array}$ \\
\hline $\begin{array}{l}\text { Severely } \\
\text { Deficient }\end{array}$ & $20(36.4)$ & $14(25.5)$ & $8(14.5)$ & $7(12.7)$ & $34(61.8)$ & $22(40.0)$ \\
\hline $\begin{array}{l}\text { Moderately } \\
\text { Deficient }\end{array}$ & $22(40.0)$ & $20(36.4)$ & $11(20.0)$ & $19(34.5)$ & $4(7.3)$ & $21(38.2)$ \\
\hline $\begin{array}{l}\text { Mildly } \\
\text { Deficient }\end{array}$ & $4 \quad(7.3)$ & $3(5.5)$ & $1(1.8)$ & 7 (12.7) & $4(7.3)$ & $8(14.5)$ \\
\hline $\begin{array}{l}\text { Low } \\
\text { Average }\end{array}$ & $4 \quad(7.3)$ & $6(10.9)$ & $13(23.6)$ & $8(14.5)$ & $1(1.8)$ & $1(1.8)$ \\
\hline Average & $5 \quad(9.1)$ & $10(18.2)$ & $22(40.0)$ & $13(23.6)$ & $12(12.5)$ & $3(5.5)$ \\
\hline $\begin{array}{l}\text { High } \\
\text { Average/Superior }\end{array}$ & $\begin{array}{ll}0 & (0.0)\end{array}$ & $2 \quad(3.6)$ & $\begin{array}{ll}0 & (0.0)\end{array}$ & $1(1.8)$ & $\begin{array}{ll}0 & (0.0)\end{array}$ & $0(0.0)$ \\
\hline
\end{tabular}


Table 6

Frequencies and Percentages by RBANS Indexes for Drivers $(n=96)$

\begin{tabular}{|c|c|c|c|c|c|c|}
\hline & $\begin{array}{l}\text { Immediate } \\
\text { Memory } \\
\mathrm{n}(\%)\end{array}$ & $\begin{array}{l}\text { Visuospatial/ } \\
\text { Constructional } \\
\mathrm{n}(\%)\end{array}$ & $\begin{array}{l}\text { Language } \\
\mathrm{n}(\%)\end{array}$ & $\begin{array}{l}\text { Attention } \\
\mathrm{n}(\%)\end{array}$ & $\begin{array}{l}\text { Delayed } \\
\text { Memory } \\
\mathrm{n}(\%)\end{array}$ & $\begin{array}{l}\text { Total } \\
\text { Score } \\
\mathrm{n}(\%)\end{array}$ \\
\hline $\begin{array}{l}\text { Severely } \\
\text { Deficient }\end{array}$ & $32(33.3)$ & $16(16.7)$ & $6 \quad(6.3)$ & $13(13.5)$ & $39(40.6)$ & $26(27.1)$ \\
\hline $\begin{array}{l}\text { Moderately } \\
\text { Deficient }\end{array}$ & $13(13.5)$ & $16(16.7)$ & $6 \quad(6.3)$ & $16(16.7)$ & $12(12.5)$ & 19 (19.8) \\
\hline $\begin{array}{l}\text { Mildly } \\
\text { Deficient }\end{array}$ & $8 \quad(8.3)$ & $9 \quad(9.4)$ & $13(13.5)$ & $4 \quad(4.2)$ & $5 \quad(5.2)$ & $9 \quad(9.4)$ \\
\hline $\begin{array}{l}\text { Low } \\
\text { Average }\end{array}$ & $4 \quad(4.2)$ & $15(15.6)$ & $17(17.7)$ & $10(10.4)$ & $9 \quad(9.4)$ & $12(12.5)$ \\
\hline Average & $34(35.4)$ & $32(33.3)$ & $49(51.0)$ & $46(47.9)$ & $20(20.8)$ & $25(26.0)$ \\
\hline $\begin{array}{l}\text { High } \\
\text { Average }\end{array}$ & $\begin{array}{ll}0 & (0.0)\end{array}$ & $2(3.6)$ & $0 \quad(0.0)$ & $0 \quad(0.0)$ & $0 \quad(0.0)$ & $\begin{array}{ll}0 & (0.0)\end{array}$ \\
\hline Superior & $\begin{array}{ll}0 & (0.0)\end{array}$ & $\begin{array}{ll}0 & (0.0)\end{array}$ & $0 \quad(0.0)$ & $0 \quad(0.0)$ & $0 \quad(0.0)$ & $\begin{array}{ll}0 & (0.0)\end{array}$ \\
\hline
\end{tabular}

Participants also differed in their performance on the Trails B. As described in Chapter 3, the Trails B measures the participant's ability to maintain attention to task, switch tasks, and scan an area or the environment. The score of the Trails B reflects the accuracy and the ability to complete the test within a five minute time frame. The final score is categorized as average to severely deficient based on total time to complete the task. The RBANS visuospatial and attention indexes provide similar measurement of the cognitive tasks measured in the Trails B, attention, task-switching, and scanning. The degree of impairment in drivers was greater as measured by the Trails B than by the RBANS indexes of visuospatial and attention. The results of the Trails B again show that $55.4 \%$ of drivers were categorized as within normal limits or superior versus non-drivers $34.5 \%$ indicating better cognitive ability. Both groups had several participants who 
scored as severely deficient: drivers $32.3 \%$ severely or moderately deficient versus $52.7 \%$ non-drivers. Table 7 provides the results of the Trails B.

Table 7

Frequencies and Percentages per Classification of Impairment for Trails $B$ Non-driver $(\mathrm{n}=55) \quad$ Driver $(\mathrm{n}=96)$

Severely deficient

\begin{tabular}{cc}
$\mathrm{n}(\%)$ & $\mathrm{n}(\%)$ \\
\hline $19(34.5)$ & $22(22.9)$
\end{tabular}

Moderately deficient

$10(18.2)$

Low average

Within normal limits

$18(32.7)$

$47(49.1)$

Superior or high average

$1(1.8)$

$6(6.3)$

\section{Description of Depressive Symptoms}

The Geriatric Depression Scale screens for the number of depressive symptoms an individual has experienced during the previous week. Although the range of scores was similar, non-drivers had a mean score of $11.6(S D=7.4)$ indicative of mild depressive symptoms, while drivers had a mean score of $7.9(S D=5.3)$ indicative of no depressive symptoms.

\section{Description of Functional Abilities}

Hand-grip strength and gait measurements were used as measures of functional ability in this study. More non-drivers had moderate to severe deficiencies than drivers (Table 8). Whereas hand-grip strength provides a measurement of upper body functional ability, gait provides a description of the individual's ambulation. Non-drivers (41.3\%) more often used an assistive device than did drivers (3.1\%). 
Table 8

Frequencies and Percentages of Handgrip Strength in Dominant and Non-Dominate Hand

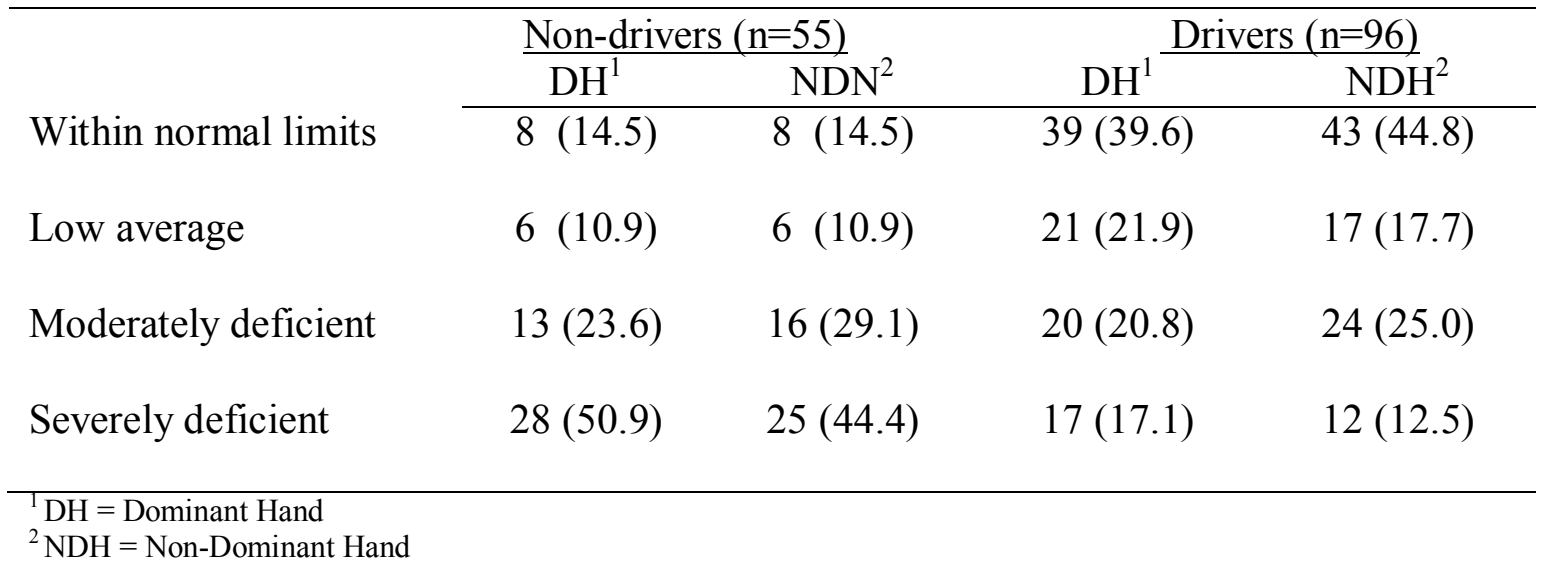

\section{Relationships Among Variables}

Relationships existed between several of the independent variables and driving status. Point biserial correlations were computed among the continuous independent variables of age, five index scores of the RBANS, the Total RBANS score, the GDS, and the Trails B. The results of the point biserial correlational analysis presented in Table 9, show age was the only variable statistically significant related to driving status at -.378 . Of the remaining point biserial correlations directly related to driving status were statistical significant but correlations were less than .30 indicating weak correlations. In general, the results indicate as a person ages, they are less likely to continue to drive.

Additionally, the Choice model illustrates potential interrelationships among the concepts of cognitive status, depressive symptoms, social support, and functional status. The results of the point biserial correlational analysis presented in Table 9 show 13 out of the 35 correlations were statistically significant and greater than .35 . These results suggest the inter-relationships between the RBANS indexes and Total RBANS score 
have a greater relationship to the choice to continue to drive. In general, these interrelationships suggest a combination of cognitive skills, such as immediate memory, attention, visuospatial, attention, and delayed memory, may play a role in continuing to drive than only one measure of cognitive skills. The inter-relationship between age, delayed memory, and total RBANS score were statistically significant but less than .30 indicating a weak relationship. The inverse inter-relationship between GDS and the cognitive skills of visuospatial/constructional and attention were statistically significant but less than .30 indicating a weak relationship. The inverse relationship suggests that as depressive symptoms increase, the individual may have difficulty with maintaining attention and space relationships when driving. In this sample, the inter-relationship between variables may play a greater role in the choice to continue to drive than the direct relationships with driving status.

Table 9

Correlations Among Driving Status, RBANS Indexes, GDS, and Trails B

\begin{tabular}{|c|c|c|c|c|c|c|c|c|c|}
\hline & Age & $\begin{array}{l}\text { Immediate } \\
\text { Memory }\end{array}$ & $\mathrm{V} / \mathrm{C}^{1}$ & Language & Attention & $\begin{array}{l}\text { Delayed } \\
\text { Memory }\end{array}$ & $\begin{array}{l}\text { Total } \\
\text { Score }\end{array}$ & GDS & $\begin{array}{c}\text { Trails } \\
\text { B }\end{array}$ \\
\hline $\begin{array}{c}\text { Driving } \\
\text { Status }\end{array}$ & $-.378 * *$ & $.217 * *$ & $.243 * *$ & $.215^{* *}$ & $.192 *$ & $.218^{* *}$ & $.290 * *$ & $.272 * *$ & -.003 \\
\hline Age & & -.158 & -.137 & -.147 & .021 & $-.184 *$ & $-.164 *$ & -.023 & .147 \\
\hline $\begin{array}{l}\text { Immediate } \\
\text { Memory }\end{array}$ & & & $.259 * *$ & $.516^{* *}$ & $.541 * *$ & $.786 * *$ & $.849^{* *}$ & .073 & -.042 \\
\hline $\mathrm{V} / \mathrm{C}^{1}$ & & & & $.348^{* *}$ & $.407^{* *}$ & $.241^{* *}$ & $.583 * *$ & $-.266^{* *}$ & -.101 \\
\hline Language & & & & & $.486^{* *}$ & $.533 * *$ & $.700 * *$ & -.076 & -.205 \\
\hline Attention & & & & & & $.419 * *$ & $.746^{* *}$ & $-.249 * *$ & -.110 \\
\hline $\begin{array}{l}\text { Delayed } \\
\text { Memory }\end{array}$ & & & & & & & $.828 * *$ & .135 & -.061 \\
\hline $\begin{array}{l}\text { Total } \\
\text { Score }\end{array}$ & & & & & & & & -.083 & -.085 \\
\hline GDS & & & & & & & & & -.006 \\
\hline
\end{tabular}

${ }^{1}$ Visuospatial/Constructional $* p \leq .05,{ }^{* *} p \leq .01$ 
The literature suggests the individual's characteristics may relate to their choice to retire from driving. Chi-square tests were conducted to assess whether the categorical independent variables age, marital status, gender, hand-grip, or gait affected the choice to retire from driving. All variables were statistically significant except for gender and non-dominate hand-grip. The insignificant finding for gender differs from previous studies. Few if any studies have used hand-grip as a measurement of functional status indicating a potential important finding (Table 10).

Table 10

Chi-square Analysis of Age, Gender, Marital Status, Handgrip, and Gait

\begin{tabular}{lcccccc}
\hline & Age & Gender & $\begin{array}{c}\text { Marital } \\
\text { Status }\end{array}$ & $\begin{array}{c}\text { Handgrip- } \\
\text { DH }\end{array}$ & $\begin{array}{c}\text { Handgrip- } \\
\text { NDH }\end{array}$ & Gait \\
\hline Chi-Square & $45.000^{\mathrm{b}}$ & $.801^{\mathrm{a}}$ & $6.364^{\mathrm{a}}$ & $6.854^{\mathrm{b}}$ & $10.563^{\mathrm{b}}$ & $155.298^{\mathrm{c}}$ \\
df & 3 & 1 & 1 & 3 & 3 & 2 \\
Asymp. Sig. & .000 & .371 & .012 & .077 & .014 & .000 \\
\hline
\end{tabular}

a 0 cells $(.0 \%)$ have expected counts less than 5 . The minimum expected count is 75.5 .

b 0 cells $(.0 \%)$ have expected counts less than 5 . The minimum expected count is 37.8

c 0 cells $(0 \%)$ have expected cell counts less than 5 . The minimum expected cell frequency is 50.3

\section{Predicting Driving Retirement}

The final sample size $(\mathrm{N}=151$; non-drivers, $\mathrm{n}=55$, drivers, $\mathrm{n}=96)$ required a reduction in study variables to a maximum of six to achieve the best prediction model. This number of variables is directly related to the final sample size of non-drivers. Using more variables in a small sample generally does not provide the best or optimal prediction model (Tabachnick \& Fidell, 2007). Univariate logistic regression analyses were run to identify which independent variables should be used in the regression model to predict driving choice. To run the univariate regressions, new variables were created for each category in age, marital status, gait, handgrip, and Trails B. For example, in the categorical variable of marital status, one categorical variable was created, married. The 
categorical variable of non-married, which included single, divorced, and widowed, was created as a reference variable. This creation of new variables allowed for univariate logistic regression to determine if one category of marital status was statistically significant when compared to unmarried category (Table 11). After creation of the new variables on the remaining categorical variables, data screening revealed multicollinearity of the independent variables immediate and delayed memory, as well as multiple outliers. Both independent variables of immediate and delayed memory remained in the analysis because intellectually the tests are different and, therefore, were anticipated to potentially add to the statistical analysis. No consistent outliers were found and therefore no cases were deleted. The deletion of multiple outliers would decrease the sample size. To enhance understanding of each logistic regression model, an illustration of the Choice Framework with the attached independent variables provides a visual representation. 


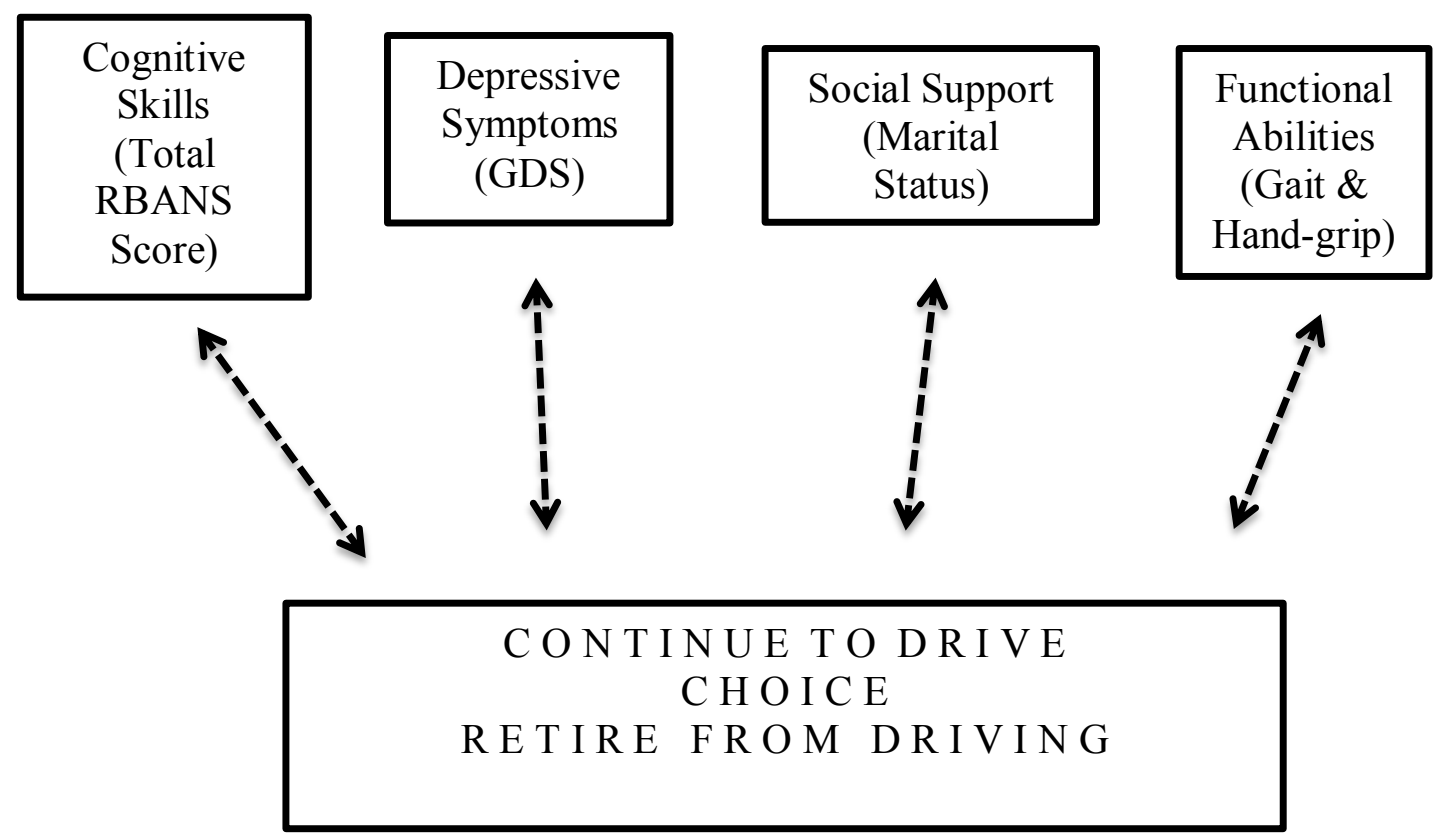

Figure 4. Regression Analysis Using the Independent Variables of the CHOICE Framework

Backward stepwise logistic regression was conducted to determine which independent variables representing the major concepts of the CHOICE Framework were predictors of driving status (see Figure 4). Regression results indicated the overall model of the five predictors (total RBANS score, GDS, married, independent gait, and severely impaired hand-grip, both $\mathrm{DH}$ and $\mathrm{NDH}$ ) was statistically reliable in distinguishing between drivers and non-drivers (-2 Log Likelihood $=126.036$; Hosmer and Lemeshow test of Goodness of Fit $=\chi^{2}(8)=4.33, p=.83$ ). The model correctly classified $84.8 \%$ of cases. In the multivariate analysis (Table 12), the independent predictors of driving retirement were total RBANS score $(\mathrm{OR}=1.04,95 \% \mathrm{CI}=[1.02-1.06], p=.018$, and independent gait $(\mathrm{OR}=22.45,95 \% \mathrm{CI}=[5.63-89.55], p<.000)$. The odds ratio $(\mathrm{OR})$ of the total RBANS score indicated in this model, drivers with less cognitive impairment are more likely to continue to drive and the small confidence interval (CI) add to the 
likelihood of this occurrence. Whereas the combination of the OR and CI with independent gait, although statistically significant is less predictive.

No additional combination of variables was statistically reliable in predicting

driving status.

Table 11

Univariate Statistics for Logistic Regression

\begin{tabular}{lrcc}
\hline Variable & OR & CI & $p$ value \\
\hline RBANS Scales & & & \\
$\quad$ Immediate Memory & 1.02 & $1.00-1.04$ & .000 \\
$\quad$ Visuospatial & 1.03 & $1.01-1.05$ & .004 \\
$\quad$ Language & 1.03 & $1.01-1.06$ & .011 \\
$\quad$ Attention & 1.02 & $1.00-1.04$ & .021 \\
$\quad$ Delayed Memory & 1.02 & $1.01-1.04$ & .009 \\
Total RBANS Score & 1.04 & $1.02-1.06$ & .001 \\
Trails B & & & \\
$\quad$ Above or Superior & 3.60 & $.42-30.71$ & .242 \\
$\quad$ Normal & 1.97 & $.99-3.94$ & .054 \\
$\quad$ Mildly deficient & .98 & $.36-2.66$ & .968 \\
$\quad$ Moderately deficient & .47 & $.18-1.23$ & .122 \\
& & & \\
GDS & .91 & $.87-.96$ & .000 \\
Gait & & & \\
$\quad$ Independent & 27.80 & $7.84-98.54$ & .000 \\
Hand-grip Dominant Hand & & & \\
$\quad$ Low average & 2.29 & $.87-6.07$ & .097 \\
$\quad$ Moderately deficient & .85 & $.36-1.88$ & .689 \\
$\quad$ Severely deficient & .21 & $.10-.47$ & .000 \\
Hand-grip Non-dominant Hand & & & \\
$\quad$ Low average & 1.76 & $.65-4.76$ & .268 \\
$\quad$ Moderately deficient & .81 & $.39-1.71$ & .584 \\
$\quad$ Severely deficient & .17 & $.08-.38$ & .000 \\
Age & & & \\
70-79 & 1.91 & $.93-3.91$ & .079 \\
80-89 & .44 & $.22-.87$ & .018 \\
90+ & 11.63 & $1.36-99.36$ & .025 \\
Gender & .76 & $1.37-5.54$ & .004 \\
Married & .30 & $.15-.60$ & .001 \\
\hline & & & \\
\hline
\end{tabular}


Table 12

Multivariate Statistics for Logistic Regression

\begin{tabular}{lccc}
\hline Variable & $\underline{\text { OR }}$ & $\underline{95 \% \text { CI }}$ & $\underline{p \text { value }}$ \\
\hline RBANS score & 1.03 & $1.00-1.07$ & .017 \\
GDS & .96 & $.86-1.02$ & .140 \\
Married & 2.07 & $.79-5.42$ & .137 \\
Handgrip DH (severe impairment) & .66 & $.13-3.43$ & .625 \\
Handgrip NDH (severe impairment) & .37 & $.06-1.83$ & .336 \\
Independent gait & 22.45 & $5.63-89.55$ & .000 \\
\hline
\end{tabular}

Chapter 4 provided the statistical analysis of the proposed research questions.

Chapter 5 provides a discussion of the relationship between the statistical analysis and the research questions. 


\section{CHAPTER V}

\section{DISCUSSION}

Chapter five is a discussion of the main findings of this study, and posits answers for the research questions based on the analysis of the variables within this sample. The main findings of this study are: cognitive function and physical function were predictors of choice to retire from driving; non-drivers and drivers were both found to be mildly cognitive impaired, but non-drivers had greater numbers who were moderately to severely impaired; gender was not statistically significant in driving retirement; the relationships between variables directly related to driving status were weak or nonsignificant but interrelationships between variables were significant, GDS scores had an inverse relationship to measures of cognitive skills; These will be discussed further by research question.

\section{Research Question One}

Research question one focused on describing the characteristics of the sample by driving status: non-driver versus driver. The results of the study indicated that nondrivers tended to be older, not married, and female. These characteristics are similar to findings in several studies (Anstey et al., 2006: Brayne et al., 2000; Carr, Douchek, Meuser, Morris, 2006(a); Delling et al., 2001; Oxley \& Charlton, 2009). An explanation for this finding might be older female adults, particularly over the age of 80 , relied on 
their spouses throughout the years for driving and may consider driving as less important. This explanation may not hold true for the aging baby boomers. This aging group, particularly females, is more independent as a result of social events, such as the women's movement in the late sixties and early seventies, giving them a greater sense of independence. As time goes on, more women may have difficulty retiring from driving. The cognitive abilities further describe the sample. Based on the scores of the Mini-Mental Status Exam (MMSE), both non-drivers and drivers were classified as having mild cognitive impairment. This classification of mild cognitive impairment is not typical of older adults. The National Institute of Aging (2011) estimates $11 \%$ to $20 \%$ of adults age 65 and older worldwide have mild cognitive impairment. The results of the Repeatable Battery for the Assessment of Neuropsychological Status (RBANS) provided additional explanation of the cognitive characteristics of both groups. Drivers tended to be less impaired with a greater percentage categorized as average to above average or superior, whereas more non-drivers were moderately impaired or severely. Interestingly, drivers had moderate to severe cognitive impairment within all indexes of the RBANS, with more pronounced deficiencies in the areas of immediate memory and delayed memory. The results of the Trails Making Test Part B (Trails B) also indicated that drivers had severe to moderate cognitive impairment in the areas of attention, taskswitching, and scanning, important attributes for safe driving. Although these results do not vary greatly from previous research findings, the results reaffirm that older adults continue to drive irrespective of their cognitive abilities (Erten-Lyons, 2008; Ott et al., 2008; \& Talbot et al., 2009). 
The Geriatric Depression Scale (GDS) scores provide additional evidence that varied by driving status. Non-drivers tended to have more depressive symptoms than drivers, with the average scores classifying non-drivers with mild depressive symptoms versus drivers with fewer to no depressive symptoms. It is difficult to know whether driving played a role in the number of depressive symptoms but the literature supports that non-drivers tend to have more depressive symptoms (Edwards et al, 2009; Kohler et al, 2010). It is interesting to note that both driver and non-driver groups had individuals with scores as high as 26 out of a maximum score of 30 , indicating the presence of a "severe" number of depressive symptom. The research setting provides treatment for psychological disorders, such as depression as well as cognitive disorders such as dementia. The severity or number of depressive symptoms in both groups may be a result of the research setting rather than a significant finding but individuals continued to drive irrespective of the presence of depressive symptoms. The research setting is a center for treatment of psychological disorders, such as depression as well as cognitive disorders such as dementia, and it is possible the sample was biased as a result. The severity of depressive symptoms may be indicative of a co-morbid condition of depression rather than driving status but potentially strengthens the relationship between depressive symptom and the choice to continue to drive as illustrated in the CHOICE Framework. Both groups had severe depressive symptoms; non-drivers $14.5 \%$ and drivers 5.2\%. The National Institute of Mental Health states that depressive symptoms in older adults tend to be under-recognized and under-treated (2010) but estimate nearly $5.0 \%$ of adults age 50 and older have some form of depression. 
The final characteristic of the sample was functional status, which was measured using gait and handgrip. Gait, measured as independent compared to use of assistive device. Non-drivers tended to use some type of assistive device for mobility more than drivers. These results were not unexpected but the results indicate drivers may have reduced strength in their lower extremities highlighting a potential risk for unsafe driving. The information available to the researcher did not indicate whether the driver had any special car adaptations that might improve driving safety. Although the characteristics of this sample are similar to other research findings, measurement of functional abilities differed in other studies (Edwards et al., 2008; Edward et al., 2009; \& O'Conner, Edwards, Wadley, \& Crowe, 2010). These researchers found reduced functional ability either by demonstration of Turn $360^{\circ}$ or self-reporting of ADL's and IADL's. Collectively, these results indicate that older drivers continue to drive irrespective of cognitive abilities, depressive symptoms, or functional status.

The results of tests for handgrip strength indicated both non-drivers and drivers had severe difficulty with handgrip strength in their dominant and non-dominant hands. This finding is significant with those individuals that continue to drive. Handgrip strength demonstrates the ability to grasp the steering wheel in this study. The results are less than optimal, thus potentially indicating unsafe driving practices. The strength of this finding is only confounded by unknown co-morbid conditions, such as cerebral vascular accident, hand injury, and depression. Few research studies used handgrip strength as an independent variable for functional status and driving (Anstey et al., 2006; Carr, et al., 2006(b); \& Sallinen, et al., 2010). Anstey (2006) and Carr, et al (2006b) 
found only a modest association with driving cessation, whereas, Sallinen and colleagues (2010) used handgrip measurement only of the dominant hand and as a measurement of overall muscle strength as an indication of frailty in older adults. This finding supports the hypothesized relationship between functional status and choice to continue to drive as illustrated in the CHOICE Framework. The results of this study confirm the hypothesized relationship between functional abilities and the presence of depressive symptoms (Gallo, Rebok, Tennsted, Wadley, \& Horgas, 2003). Individuals choosing to continue to drive had difficulties with functional abilities and the presence of depressive symptoms, thus confirming the relationship between these concepts and the choice to continue to drive as illustrated by the CHOICE Framework.

\section{Research Question Two}

The second research question focused on the relationships and inter-relationships between the variables of cognition, depressive symptoms, functional status, and the choice to retire from driving.

Cognitive status, depressive symptoms, and driving status demonstrated weak relationships. Although these relationships were small, they were statistically significant. Age had a moderate inverse relationship with driving re-affirming that as individuals age; they are less likely to continue to drive. Non-parametric correlations, using $\chi^{2}$, focused on relationships between driving status and the categorical variables of gender, age, marital status, hand grip, and gait. Chi-square tests indicated statistically significant relationships with age, marital status, handgrip non-dominant hand, and gait, but not gender and handgrip dominant hand. The statistically non-significant relationship of 
driving status with gender is an unexpected finding. Many studies find that males tend to continue to drive rather than females irrespective of cognitive or functional abilities (Antsey et al., 2006; Carr et al., 2006(a); Carr et al., 2006(b), \& Delling et al., 2001, \& Oxley \& Charlton., 2009). The additional statistical non-significant finding of handgrip in the dominant hand is unexpected. This finding suggests that as functional abilities decline many individuals continue to drive but few research studies used handgrip (Anstey, 2006; \& Carr et al., 2006b) as a measure for functional status and driving. This finding suggests that additional research is needed using handgrip as a variable to determine safe driving.

The inter-relationship between variables of cognitive skills, such as attention, visuospatial/constructional, and immediate memory, may play a more significant role in an individual's ability to continue to drive. Interestingly, two of three inter-relationships are similar skills (attention and visuospatial/constructional) required to successfully complete the Trails B test. Yet, the Trails B test was not statistically significant in this sample. The Trails B is an easy to administer test that can easily measure cognitive skills important for safe driving (Dobbs \& Shergill, 2013). Although these authors found the tool to be effective for identify cognitively impaired at-risk drivers, their finding suggest that it may not be useful in drivers with severe cognitive impairment. This study sample had individuals in both groups with severe to moderate cognitive impairment. This may provide additional explanation of this statistical insignificant finding. 


\section{Research Question Three}

The final research question focused on variables that may predict the choice to retire from driving. A logistic regression model was analyzed using variables selected from the CHOICE Framework and univariate logistic regression analyses. The model was statistically significant in predicting driving retirement. This model correctly classified non-drivers and drivers correctly in $84.8 \%$ of the cases. Of the five variables entered into the model, only cognitive status and functional status were statistically significant predictors of the choice to retire from driving; depressive symptoms neared significance and may have reached significance in a larger sample.

The CHOICE Framework has the potential to be foundational in developing a more complete framework that predicts the identification of individuals that require assistance in choosing to retire from driving.

\section{Limitations of Study}

This study has several limitations that affect both internal and external validity. Threats to internal validity are varied. First, the final sample size was 87 participants fewer than the 238 needed to achieve a power of 0.95 for conducting multivariate logistic regression. The lower sample size resulted from a lack of individuals meeting inclusion criteria. This is a problem of using a convenience sample and the limitation of using a single site for data collection. Second, the possibility of confounding variables, such as co-morbid medical conditions, use of medications, and test anxiety may impact the final results. The participants and/or significant other were actively seeking answers for cognitive and/or behavioral changes which may be an additional confounding 
variable. These confounding variables may be individual characteristics that may add to the CHOICE Framework, thereby adding to the predictive value of the framework. Third, most testing results were normalized prior to statistical analysis. This limitation resulted from testing results available from the redacted data. The inability to enter raw testing results and then statistically normalize the data may contribute to inaccurate or inconclusive answers to the research questions. Fourth, the decision to retain variables statistically indicative of multicollinearity and outliers might have influenced the results. Finally, a measurement of choice was not available. A clear distinction between an individual's choice to retire from driving or an external factor contributing to driving cessation is inconclusive and reference to choice should be used cautiously in this study.

Threats to external validity arise from the retrospective research design, convenience sample, and results of the MMSE. The retrospective research design is generally viewed as a pilot study. Therefore, the results of this study should be viewed as a preliminary testing of the CHOICE Framework, limiting the generalizability of the results. The research design also used a convenience sample and one data collection site. These factors should also contribute to viewing this study within the context of a pilot study. Additionally, both groups in this study fell within the category of mild cognitive impairment according to the MMSE. This also limits the ability to generalize the results to all older adults but might offer some insight to older adults with declining cognitive abilities. 


\section{Conclusions}

The literature supports the major concepts and potential inter-relationships between these concepts in the CHOICE to retire from driving. The statistical analysis yielded new information to driving retirement in older adults. The use of logistic regression and the CHOICE Framework was an innovative approach to study older adult drivers. Driving retirement may be a continuum of driving, moving to self-regulation, to retirement rather than a decisive life event (Bladock et al., 2006; Braitman \& Williams, 2011; Donorfio et al, 2008; Johnson, 2002) but older adult drivers with deficiencies in either one or all of the major concepts of the CHOICE Framework continue to drive and place the individual and others at risk for injury and/or death. This problem will continue to grow as demographics continue to shift toward a larger old adult population.

\section{Implications and Recommendations for Future Research}

The CHOICE Framework does predict driving retirement but future research is necessary to refine the model. Future studies should include variables that measure social support. The literature suggests social support plays a role in older adults retirement from driving. A prospective longitudinal design might provide insight into how an older adult choose or not to retire from driving. Measurement of Instrumental Activities of Daily Living (IADL) may be a better measurement of functional ability (Lawton \& Brody, 1969) and therefore potentially provide additional support for the inter-relationship between functional abilities and cognitive skills. Additionally, a measurement of the individual's ability or in what manner they make choices will add additional support to the CHOICE Framework. 


\section{REFERENCES}

Adams, G. A., \& Beehr, T. A. (Eds.). (2003). Retirement: Reasons, processes, and results. New York: NY: Springer Publishing Company.

Adler, G., \& Rottunda, S. (2006). Older adults' perspectives on driving cessation. Journal of Aging Studies, 20, 227-235.

Alexandersen, A., Dalen, K., \& Bronnick, K. (2009). Prediction of driving ability after inconclusive neuropsychological investigation. Brain Injury, 23, 313-321.

Antsey, K. J., Windsor, T. D., Luszcz, M. A., \& Andrews, G. R. (2006). Predicting driving cessation over 5 years in older adults: Psychological well-being and cognitive competence are stronger predictors than physical health. Journal of the American Geriatrics Society, 54, 121-126.

Ashendorf, L., Jefferson, A., O'Connor, M., Chaisson, C., Green, R., \& Stern, R. (2008). Trail Making Test errors in normal aging, mold cognitive impairment, and dementia. Archives of Clinical Neuropsychology, 23, 129-137.

Baker, R. (2006). Economic rationality and health and lifestyle choices for people with diabetes. Social Science \& Medicine, 63, 2241-2353.

Baldock, M. R., Mathias, J. L., McLean, J., \& Berndt, A. (2006). Self-regulation and driving and older drivers' abilities. Clinical Gerontologist, 30, 53-66.

Ball, K. K., Roenker, D. L., Wadley, V. G., Edwards, J. D., Roth, D. L., McGinn, G., ..., Dube, T. (2006). Can high-risk older drivers be identified through performancebased measures in a department of motor vehicles setting? Journal of the American Geriatrics Society, 54, 77-84.

Balleine, B. (2007). Neural basis of choice and decision making. The Journal of Neuroscience, 27, 8159-8160.

Barker, M., Horner, M., \& Bachman, D. (2010). Embedded indices of effort in the repeatable battery for the assessment of neuropsychological status (RBANS) in a geriatric sample. The Clinical Neuropsychologist, 24, 1064-1077.

Bauer, M. J., Rottunda, S., \& Adler, G. (2003). Older women and driving cessation. Qualitative Social Work, 2, 309-325. 
Bekhet, A., Zauszniewski, J., \& Nakhla, W. (2009). Reasons for relocation to retirement communities: A qualitative study. Western Journal of Nursing Research, 31, 462-479.

Bennett, J., Cameron, L., Brown, P., Whitehead, L., Porter, D., Ottawy-Parkes, T., \& Robinson, E. (2010). Time since diagnosis as a predictor of symptoms, depression, cognition, social concerns, perceived benefits, and overall health in cancer survivors. Oncology Nursing Forum, 37, 331-338.

Bohannon, R. W. (2008). Hand-grip dynamometry predicts future outcomes in aging adults. Journal of Geriatric Physical Therapy, 31(1), 3-10.

Botti, S., Orfali, K., \& Iyengar, S. (2009). Tragic choices: Autonomy and emotional responses to medical decisions. Journal of Consumer Research, 36, 337-352.

Bower, J. (2008). Behavioral symptoms in patients with breast cancer and survivors. Journal of Clinical Oncology, 26, 768-777.

Braitman, K. A., \& Williams, A. F. (2011). Changes in self-regulatory driving among older drivers over time. Traffic Injury Prevention, 12, 568-575.

Brayne, C., Dubouil, C., Ahmed, A., Dening, T. R., Lin-Yang, C., \& McGee, M. (2000). Very old drivers: findings from a population cohort of people aged 85 and over. International Journal of Epidemiology, 29, 704.

Burge, S. \& Street, D. (2010). Advantage and choice: Social relationships and staff assistance in assisted living. The Journals of Gerontology. Series B, Psychological Sciences and Social Sciences, 65B, 358-369.

Bush, A. J., Morris, S. N., Millham, F. H., \& Issacson, K. B. (2011). Women's preferences for minimally invasive incision. Journal of Minimally Invasive Gynecology, 18, 640-643.

Carr, D. B., Douchek, J. M., Meuser, T. M., \& Morris, J. C. (2006a). Older adult drivers with cognitive impairment. American Family Physician, 73, 1029-1036.

Carr, D. B., Flood, K. L., Steger-May, K., Schechtman, K. B., \& Binder, E. F. (2006b). Characteristics of frail older adult drivers. Journal of the American Geriatrics Society, 54, 1125-1129.

Carr, D., \& Moorman, S. (2009). End-of-life treatment preferences among older adults: An assessment of psychosocial influences. Sociological Forum, 24, 754-778. 
Castel, A., McCabe, D., \& Roediger, H. (2007). Illusions of competence and overestimation of associative memory for identical items: Evidence from judgments of learning. Psychonomic Bulletin Review, 14(1), 107-111.

Choice. (2012). Merriam-Webster dictionary and thesaurus. Retrieved 03/14, 2012, from http://www.merriam-webster.com/

Clark, M., \& Diamond, P. (2010). Depressive symptoms in family caregivers of elders: A theoretical model of caregiver burden, sociotropy, and autonomy. Research in Nursing Health, 33, 20-34.

Colsher, P. L., \& Wallace, R. B. (1993). Geriatric assessment and driver functioning. Clinical Geriatric Medicine, 9, 365-375.

Croston, J., Meuser, T. M., Berg-Weger, M., Grant, E. A., \& Carr, D. B. (2009). Driving retirement in older adults with dementia. Topics in Geriatric Rehabilitation, $25,154-162$.

D'Ambrosio, L. A., Coughlin, J. F., Mobyde, M., Carruth, A., Hunter, J. C., \& Stern, R. A. (2009). Caregiver communications and the transition from driver to passenger among people with dementia. Topics in Geriatric Rehabilitation, $25,33-42$.

Delling, A. M., Sehgal, M., Sleet, D. M., \& Barrett-Connor, E. (2001). Driving cessation: What older former drivers tell us. Journal of the American Geriatrics Society, 49, 431-435.

Dobbs, , B. M. \& Shergill, S. S. (2013). How effective is the Trail Making Test (Parts A and B) in identifying cognitively impaired drivers? Age \& Ageing, 42(5), 577581 .

Donorfio, L. K., D'Ambrosio, L. A., Coughlin, J. F., \& Mobyde, M. (2008). Health, safety, self-regulation and the older driver: It's not a matter of age. Journal of Safety Research, 39, 551.

Donorfio, L. K., Mobyde, M., Coughlin, J. F., \& D'Ambrosio, L. A. (2008). A qualitative exploration of self-regulation behaviors among older drivers. Journal of Aging Social Policy, 20, 323-339.

Donsanjih, S., Matta, J. M., \& Bhandari, M. (2009). The final straw: A qualitative study to explore patient decisions to undergo total hip arthroplasty. Archive of Orthopedic, 129, 719-727. 
Duff, K., Beglinger, L., Schoenberg, M., Patton, D., Mold, J., Scott, J., \& Adams, R. (2005). Test-retest stability and practice effects of the RBANS in a community dwelling elderly sample. Neuropsychology, development, and cognition. Section A. Journal of Clinical and Experimental Neuropsychology, 27, 565-575.

Duff, K., Langbehn, D., Schoenberg, M., Moser, D., Baade, L.,Mold, J., ... \& Adams, R. (2009). Normative data on a psychometric properties of verbal and visual indexes of the RBANS in older adults. Clinical Neuropsychology, 23, 39-50.

Eby, D. W., \& Molnar, L. (2008). North American license policies workshop. 2008 North American License Policies Workshop Proceedings. Washington, D. C. , June 1-175.

Edwards, J. D., Ross, L. A., Ackerman, M. L., Small, B. J., Bradley, S., Dodson, J. E. (2008). Longitudinal predictors of driving cessation among older adults from the ACTIVE clinical trial. The Journals of Gerontology Series B. Psychological Sciences and Social Sciences, 63B, 6-12.

Edwards, J. D., Perkins, M., Ross, L. A., \& Reynolds, S. L. (2009). Driving status and three-year mortality among community-dwelling older adults. The Journals of Gerontology Series A Biological Sciences and Medical Sciences, 64, 300-305.

Elit, L., Charles, C., Dimitry, S., Tedford-Gold, S., Gafni, A., Gold, I., \& Whelan, T. (2010). It's a choice to move forward: Women's perceptions about treatment decision making in recurrent ovarian cancer. Psycho-Oncology, 19, 318-325.

Erikson, E. H. (1982). The life cycle completed. New York, NY: Horton.

Erten-Lyons, D. (2008). When should patients with Alzheimer's disease stop driving? Neurology, 70, e45-e47.

Federman, A., Wisinversky, J., Wolf, M., Leventhal, H., \& Halm, E. (2010). Inadequate health literacy is associated with suboptimal health beliefs in older asthmatics. Journal of Asthma, 47, 620-626.

Folstein, M. F., Folstein, S. E., \& McHugh, P.R. (1975). Mini-Mental Status Examination: a practical method for grading the cognitive state of patients for the clinician. Journal of Psychiatric Research, 12(3), 189-198.

Ford, M. E., Tilley, B. C., \& McDonald, P. E. (1998a). Social support among AfricanAmerican adults with diabetes, part 2: A review. Journal of the National Medical Association, 90, 425-432. 
Ford, M. E., Tilley, B. C., \& McDonald, P. E. (1998b). Social support among AfricanAmerican adults with diabetes. Part 1: Theoretical framework. Journal of the National Medical Association, 90, 361-365.

Freeman, E. E., Gange, S. J., Munoz, B., \& West, S. K. (2006). Driving status and risk of entry into long-term care in older adults. American Journal of Public Health, 96, 1254-1259.

Friedland, J., Rudman, D. L., Chipman, M., \& Steen, A. (2006). Reluctant regulators: Perspectives of family physicians on monitoring seniors' driving. Topics of Geriatric Rehabilitation, 22, 531-60.

Gallo, J. J., Rebok, G. W., Tennsted, S., Wadley, V. G., \& Horgas, A. (2003). Linking depressive symptoms and functional disability in late life. Aging \& Mental Health, 7, 469-480.

Goodwin, J., Zhang, D., \& Ostir, G. (2004). Effect of depressive symptoms on diagnosis, treatment, and survival of older women with breast cancer. Journal of American Geriatrics Society, 52, 106-111.

Gumus, M., Ustaalioglu, B., Garip, M., Kizitan, E., Billici, A., Seker, M., ..., \& Turhal, N. (2010). Factors that affect patient's decision-making about mastectomy or breast conserving surgery, and the psychological effect of this choice on breast cancer patients. Breast Care, 5, 164-168.

Gurland, B., \& Gurland, R. (2009a). The choices, choosing model of quality of life: Description and rationale. International Journal of Geriatric Psychiatry, 24, 90-95.

Gurland, B., \& Gurland, R. (2009b). The choices, choosing model of quality of life: Linkages to a science base. International Journal of Geriatric Psychiatry, 24, 84-89.

Gurland, B., Gurland, R., Mitty, E., \& Toner, J. (2009). The choices, choosing model of quality of life: Clinical evaluation and intervention. Journal of Interprofessional Care, 23, 110-120.

Ha, Y., Park, S., \& Ahn, H. (2009). The influence of categorical attributes on choice context effects. Journal of Consumer Research, 36, 463-477.

Han, S. (2007). Feelings and consumer decision-making: The appraisal-tendency framework. Journal of Consumer Psychology, 17, 158-168. 
Henwood, F., Harris, R., \& Spoel, P. (2011). Informing health? Negotiating the logic of choice and care in everyday practices of 'healthy living.' Social Science \& Medicine, 72, 2026-2032.

Herzog, C. (2009). Use it or lost it: An old hypothesis, new evidence, and an ongoing controversy. In H. B. Bosworth, \& D. Herzog (Eds.), Aging and cognition (1st ed., pp. 161-179). Washington, D. C.: American Psychological Association.

Hirth, V. A., Davis, B., Fridriksson, J., \& Rorden, C. (2007). Cognitive performance and neural correlates of detecting driving hazards in healthy older adults. Dementia and Geriatric Cognitive Disorders, 24, 335-342.

Ingley, S., Chinnaswamy, S., \& Devakumar, M. (2009). A community based survey of cognitive functioning, highway-code performance and traffic accidents in a cohort of older drivers. International Journal of Geriatric Psychiatry, 24, 247253.

Institute for Insurance Highway Safety. (2014). Fit for the road: Older drivers' crash rates continue to drop. Status Report, 49(1). Retrieved February 28, 2014 from http://www.iihs.org/iihs/sr/statusreport/article/49/1/1

Johnson, J. E. (1998). Older rural adults and the decision to stop driving: The influence of family and friends. Journal of Community Health Nursing, 15, 205216.

Johnson, J. E. (2002). Why rural elders drive against advice. Journal of Community Health Nursing, 19, 237-244.

Johnson, J. (2008). Informal social support networks and the maintenance of voluntary driving cessation by older rural women. Journal of Community Health, 25, 65.72

Johnson, K. R., \& Layng, T. V. (1992). Breaking the structuralist barrier: Literacy and numeracy with fluency. American Psychologist, 47, 1475-1490.

Jones, T. C., \& Nystrom, N. M. (2012). Looking back...looking forward: Addressing the lives of lesbians 55 and older. Journal of Women \& Aging, 14, 1-2-59-76.

Joon, H., Kim, M., Shanker, S., \& Han, W. (2004). Predictors of adherence to screening mammography among Korean American women. Preventive Medicine, 39, 474-481.

Kohler, S., van Boxtel, M. P., van Os, J., Thomas, A. J., O'Brien, J. T., Jolles, J., ...Allardyce, J. (2010). Journal of the American Geriatric Society, 58(5), 873879. 
Lange, J. W. (2012). The nurse's role in promoting optimal health of older adults: Thriving in the wisdom years. Philadelphia, PA: F.A. Davis Company

Lantz, M. S. (2007). The impaired older adult driver: When is it time to stop? Clinical Geriatrics, 15, 17.

Lawton, M. P., \& Brody, E. M. (1969). Assessment of older people: Self-maintaining and instrumental activities of daily living. The Gerontologist, 9(3), 179-186.

Lezak, M. D., Howieson, D. B., \& Loring, D. W. (2004). Neuropsychological assessment (4th ed.). New York, New York: Oxford University Press.

Lindsey, A., \& Yates, B. (2004). Social support: Conceptualization and measurement instruments. In M. Frank-Stronberg, \& S. J. \& Olsen (Eds.), Instruments for clinical health-care research. (3rd ed., pp. 164-199). Sudbury, Massachusetts: Jones and Bartlett.

Marcia, J., \& Josselson, R. (2013). Eriksonian personality research and its implications for psychotherapy. Journal of Personality, 79, 1-13.

Masini, B. E., \& Barrett, H. A. (2012). Social support as a predictor of psychological and physical well-being and lifestyle in lesbian, gay, and bisexual adults aged 50 and older. Journal of Gay \& Lesbian Social Services, 20, 91-110.

Matsuoka, H., Masaki, T., Kobayashi, T., Sato, K., Mori, T., Sagiyama, M., \& Atomi, Y. (2011). Which is the preference of choice either life with a stoma or evacuatory disorder following rectal cancer surgery? HepatoGastroenterology, 58, 749-751.

Mezuk, B., \& Rebok, G. W. (2008). Social integration and social support among older adults following driving cessation. The Journals of Gerontology Series B Psychological Sciences and Social Sciences, 63B, S298-S303.

Milder, T. Y., Lipworth, W. L., Williams, K. M., Ritchie, J. E., \& Day, R. O. (2011). "It looks like me": How older patients make decisions about analgesics for osteoarthritis. Arthritis Care \& Research, 63, 1280-1286.

Molnar, L. J., \& Elry, D. W. (2009). The relationship between self-regulation and driving-related abilities in older drivers: An exploratory study. Traffic Injury Prevention, 9, 314-219.

Moore, J., Boyer, E., Safren, S., Robbins, G., Boudreaux, E., Rosen, R.,...Moss, R. (2011). Designing interventions to overcome poor numeracy and improve medication adherence in chronic illness, including HIV/aids. Journal of Medical Toxicology, 7, 133-138. 
Morrell, K. (2004). Decision making and business ethics: The implications of using image theory in preference to rational choice. Journal of Business Ethics, 50, 239-252.

National Highway Traffic Safety Administration. (2013). 2012 Motor vehicle crashes: Overview. Traffic Safety Facts. Retrieved February 28, 2014, from http:/wwwnrd.nhtsa.dot.gov/Pubs/811856.pdf

National Institute of Aging. (2011). Outlook for individuals with mild cognitive impairment. Retrieved March 18, 2013, from http://www.nia.nih.gov/alzheimers/publication/2011-2012-alzheimers-diseaseprogress-report/prevalence-alzheimers-disease

National Institute of Mental Health. (2010). Older adults: Depressive symptoms and suicide facts. Retrieved December 29, 2010, from http://www.nimh.nih.gov/health/publications/older-adults-depressive symptomsand-suicide-facts-fact-sheet/index.shtml

O'Connor, M., Edwards, J., Wadley, V., \& Crowe, M. (2010). Changes in mobility among older adults with psychometrically defined mild cognitive impairment. The Journals of Gerontology. Series B. Psychological Sciences and Social Sciences, 65B, 306-316.

Odenheimer, G. L. (2006). Driver safety in older adults: The physician's role in assessing driving skills of older patients. Geriatrics, 61, 14-21.

Older adult drivers: Get the facts. (n.d.). Retrieved December 29, 2010 from http://www.cdc.gov/motorvehiclesafety/older_adult_drivers/adultdrivers_factsheet.html

Olson, M. H., \& Hergenhahn, B. R. (2009). An introduction to theories of learning. (8th ed.). Upper Saddle River, New Jersey: Pearson Education, Inc.

Ott, B. R., Heindel, W. C., Papandonatos, G. D., Festa, B. K., Davis, J. D., Daiello, L. A., \& Morris, J. C. (2008). A longitudinal study of drivers with Alzheimer's disease. Neurology, 70, 1171-1178.

Oxley, J., \& Charlton, J. (2009). Attitudes to and mobility impacts of driving cessation: Differences between current and former drivers. Topics in Geriatric Rehabilitation, 25, 43.

Ragland, D. R., Satariano, W. A., \& MacLeod, K. E. (2004). Reasons given by older people for limitation or avoidance of driving. The Gerontologist, 44, 237-244. 
Randolph, C., Tierney, M. C., Mohr, E., \& Chase, T. N. (1998). The Repeatable Battery for the Assessment of Neuropsychological Status (RBANS): Preliminary clinical validity. Neuropsychology, development, and cognition. Section A. Journal of Clinical and Experimental Neuropsychology, 20, 310-319.

Richmond, T., Tang, S. T., Tulman, L., Fawcett, J., \& McCorkle, R. (2004). Measuring function. Sudbury, MA : Jones \& Bartlett.

Rogers, B. (2005). Developing nursing knowledge: Philosophical traditions and influences. (1st ed.). Philadelphia, PA: Lippincott, Williams \& Wilkins.

Rossen, E. (2007). Assessing older persons' readiness to move to independent congregate living. Clinical Nurse Specialist, 21(6), 292-296.

Sallinen, J., Stenholm, S., Rantanen, T., Helliovarra, M., Sainio, P., Koskinen, S. (2010). Hand-grip strength cut points to screen older persons at risk for mobility limitations. Journal of the American Geriatrics Society, 58, 1721-1726.

Sanchez-Cubillo, I., Adrover-Roig, D., Rodriquez-Sanchez, J. M., Rios-Lago, M., Tirapu, J., \& Barcelo, F. ( (2009). Construct validity of the Trail Making Test: Role of task-switching, working memory, inhibition/interference control, and visumotor ability. Journal of International Neuropsychological Society, 18, 438450 .

Schrift, R., Netzer, O., \& Kivetz, R. (2011). Complicating choice. Journal of Marketing Research, 48, 308-326.

Staplin, L., Gish, K. W., \& Sifrit, K. J. (2014). Using cognitive status to predict crash risk: Blazing new trails? Journal of Safety Research, 48, 19-25.

Tabachnick, B. G., \& Fidell, L. S. (2007). Using multivariate statistics. ( $5^{\text {th }}$ ed.). Boston, MA: Pearson Education, Inc.

Talbot, A., Bruce, I., Cunningham, D. J., Coen, R. F., Lawlor, B. A., Coakley, D., ...O'Neill, D. (2005). Driving cessation in patients attending a memory clinic. Aging \& Ageing, 34, 363-368.

Tuokko, H. A., Rhodes, R. E., \& Dean, R. (2007). Health conditions, health symptoms and driving difficulties in older adults. Age and Ageing, 36, 389-394.

Tversky, A., \& Kahneman, D. (1981). The framing of decisions and the psychology of choice. Science, 211, 453-458. 
Visser, A., Dijkstra, Kuiper, D, de Jong, P. E., Franssen, C. F., Gansevoort, R. T.,...,Reijineveld, S. A. (2009). Accepting or declining dialysis: Considerations taken into account by elderly patients with end-stage renal disease. Journal of Nephrology, 22, 794-799.

Wang, J., Novemsky, N., Dhar, R., \& Baumeister, R. (2010). Trade-offs and depletion in choice. Journal of Marketing Research, 47, 910-919.

Yesavage, J. A., Brink, T. L., Rose, T. L., Lum, O., Huang, V., Adey, M., Leirer, V. O. (1983). Development and validation of a geriatric depression screening scale: A preliminary report. Journal of Psychiatry Residency, 17(1), 37-49. 
APPENDIX

CONFIDENTIALITY AGREEMENT WITH PSYCHOLOGY SPECIALISTS, LTD 
NAME: Date of Birth:

Address: Telephone \#:

I understand that the charts I review for research are protected by privacy laws, including HITPA regulations and that all identifying information is confidential.

I agree to abide by all laws regarding confidentiality and HIPPA regulations in reviewing patient charts. All identifying information will be excluded from research and each patient chart will be assigned a number that will be kept by Psychology Specialists.

I agree that any identifying information I may encounter during my research will remain confidential, as regulated by all confidentiality laws and HUPPA regulations.

I understand that the patient charts I review are the property of Psychology Specialists, LTD, with supervision of these charts provided by Leroy R. Hall, Psy.D, who will over-see all data extraction from patient charts, completed on this research project. Psychology Specialists, LTD is contracted to provide psychological and neuropsychological services to Decatur Memorial Hospital.

I understand that any misuse of confidential information is subject to prosecution under all laws governing confidentiality and HIPPA regulations.

I understand that regardless of the legal standards regulating confidentiality, $I$, as a health care professional am bound by clear and specific ethical guidelines governing confidential information and I agree to uphold those ethical guidelines to the extent of my ability.

This data extraction provides minimal risk of harm to the patients whose charts are reviewed, as all information gathered is non-identifying demographic information (e.g. age, race, gender, referral question, diagnosis) and quantitative results.

Signed: Date:

Signed:_ Date: Leroy R. Hall, Psy.D, Supervising Clinical Psychologist

Witness: Date: 